\section{IMS}

Information

Management

School

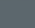

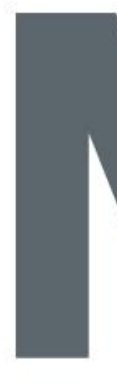
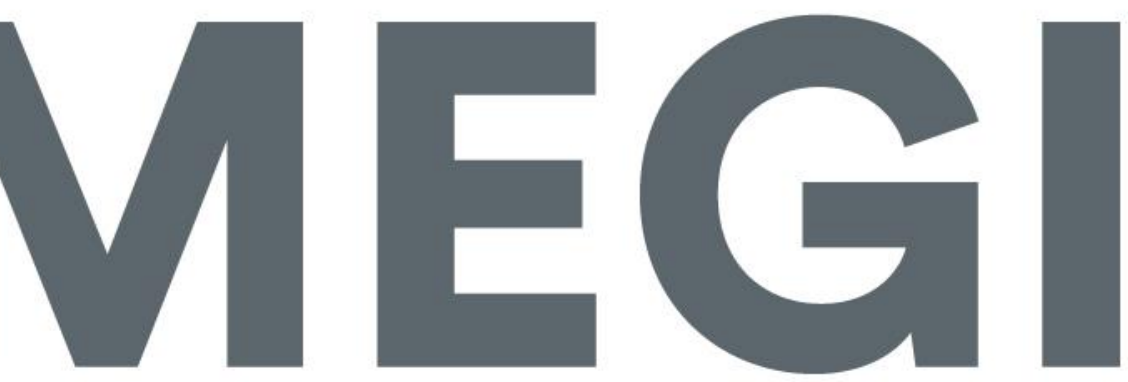

Mestrado em Estatística e Gestão de Informação Master Program in Statistics and Information Management

\title{
VOTER TURNOUT IN PORTUGAL: \\ A GEOGRAPHICAL PERSPECTIVE
}

Liliana Alexandra Silvério Raposo Guerreiro da Câmara Manoel

Dissertation presented as partial requirement for obtaining the Master's degree in Statistics and Information Management

NOVA Information Management School Instituto Superior de Estatística e Gestão de Informação 


\author{
NOVA Information Management School \\ Instituto Superior de Estatística e Gestão de Informação \\ Universidade Nova de Lisboa
}

\title{
VOTER TURNOUT IN PORTUGAL:
}

\section{A GEOGRAPHICAL PERSPECTIVE}

Liliana Alexandra Silvério Raposo Guerreiro da Câmara Manoel

Dissertation presented as partial requirement for obtaining the Master's degree in Statistics and Information Management, with a specialization in Information Analysis and Management.

Advisor: Pedro da Costa Brito Cabral, PhD

Co-supervisor: Ana Cristina Marinho da Costa, PhD

August 2019 


\section{DEDICATION (OPTIONAL)}

To Nuninho, who sleeps while I write. 


\section{ACKNOWLEDGEMENTS}

To my supervisors, Professor Ana Cristina Costa and Professor Pedro Cabral, for all the support, patience and knowledge. Without them, this would be impossible.

To Nuno, for his encouragment, support and love. 


\begin{abstract}
The decline of voter turnout in Portugal has been confirmed in the last legislative election of 2015. This fact, together with the unquestionable democratic value associated with the act of voting, leads to the discussion of the issue and emphasizes the need for additional investigation concerning the portuguese context. Particularly, it is crucial to identify the characteristics of citizens who vote, to better understand the phenomenon and think about solutions.

This work aims to identify the most significant sociodemographic variables in explaining voter turnout in continental Portugal and describe the relationship between those variables and voter turnout, including the geographical variation existing across the municipalities.

Data related to sociodemographic variables are provided from population census 2011, and turnout results concerns the legislative election of the same year. The chosen variables have been addressed in literature, both in meta-analyses studies and in country level empirical investigation.

The analysis starts with the conventional Ordinary Least Squares (OLS), and continue with more spatially sensitive methods, namely Geographically Weighted Regression (GWR) and its semiparametric extension (SGWR). The final method, SGWR, enables the investigation of local variations in turnout values, simultaneously considering that its relationship with some variables might not vary over space.

Results show that turnout is a complex process, influenced by a set of sociodemographic variables. While some variables affect turnout differently over the country (percentage of family cores with children aged less than 15, and percentage of owner-occupied houses), others affect it uniformly (percentage of graduated residents, percentage of classic families, and distance to Lisbon or Oporto the nearest). This highlights the use of a semiparametric approach to better understand turnout and for further research on voting issues.
\end{abstract}

\title{
KEYWORDS
}

Portugal; voter turnout; sociodemographic variables; semiparametric geographically weighted regression (SGWR); spatial variability. 


\section{INDEX}

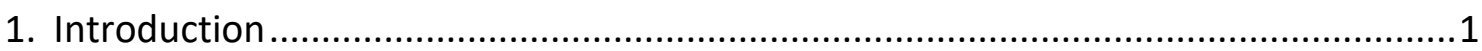

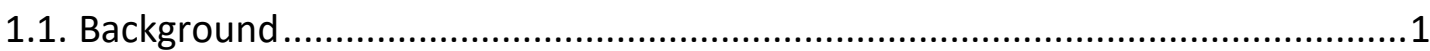

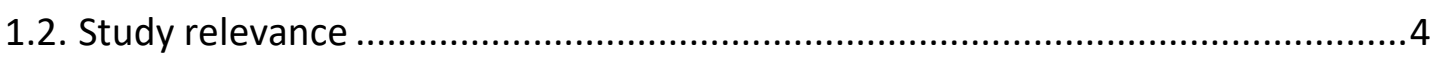

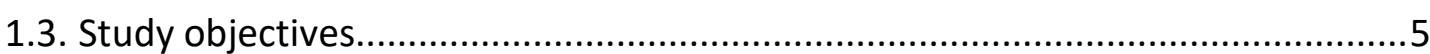

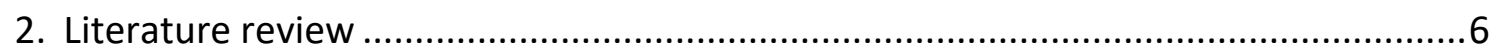

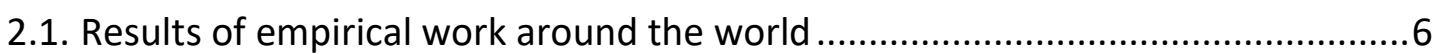

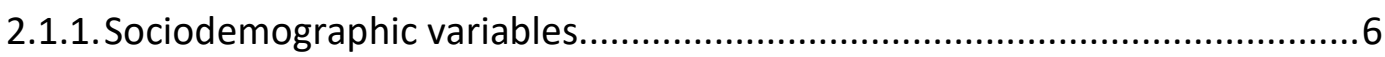

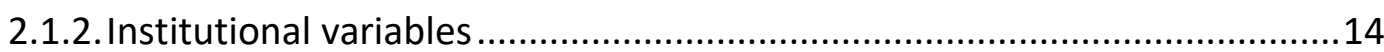

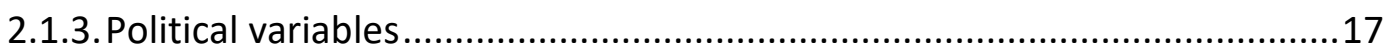

2.2. Studies concerning the portuguese context .................................................... 18

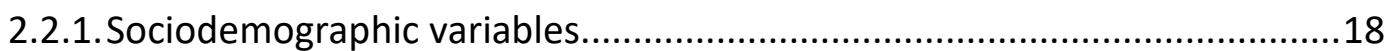

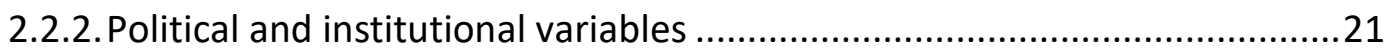

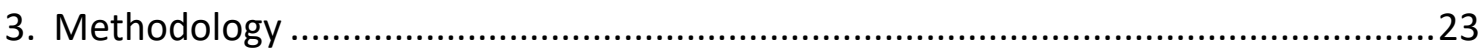

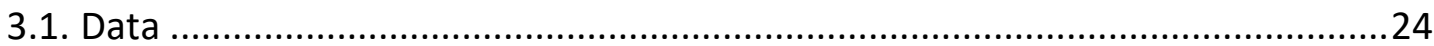

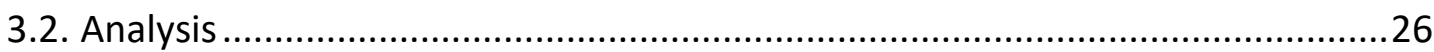

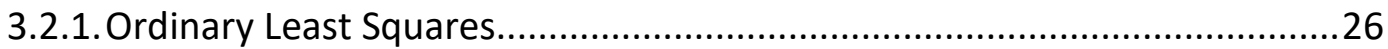

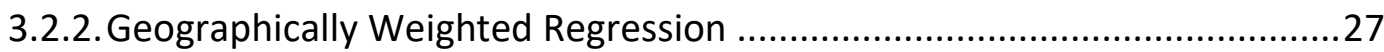

3.2.3.Semiparametric Geographically Weighted Regression.............................27

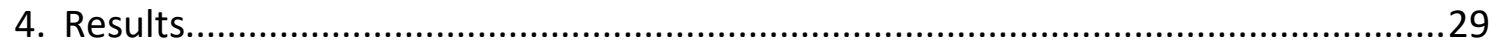

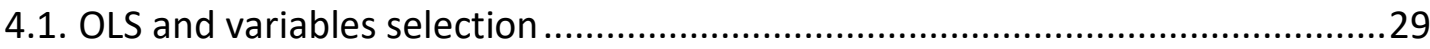

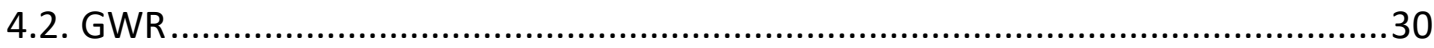

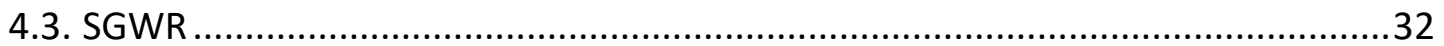

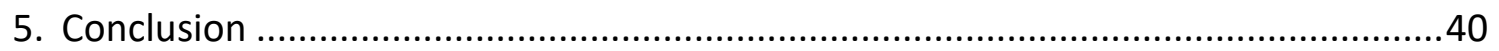

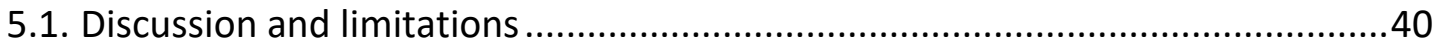

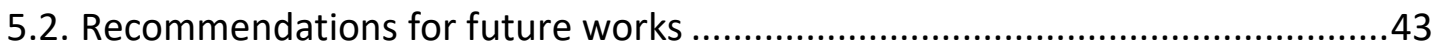

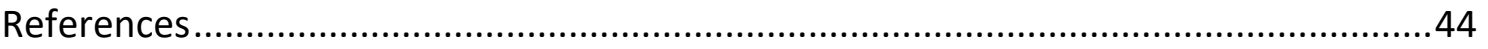




\section{LIST OF FIGURES}

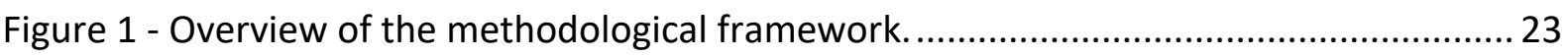

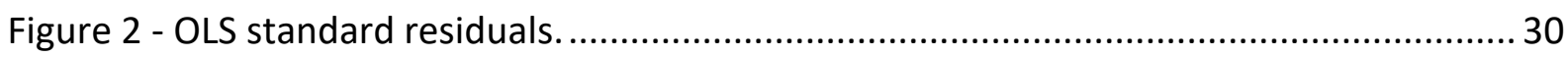

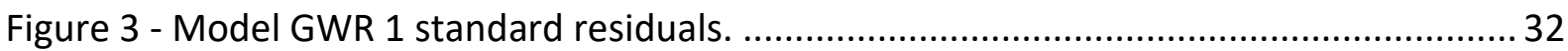

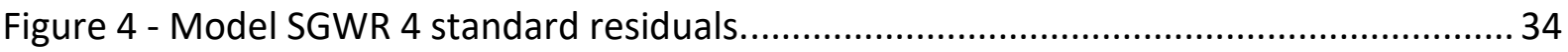

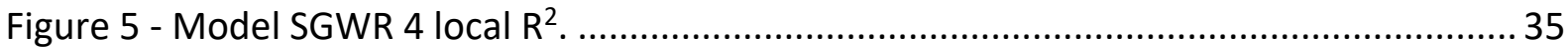

Figure 6 - Model SGWR 4 local coefficient estimates of variable «percentage of family cores

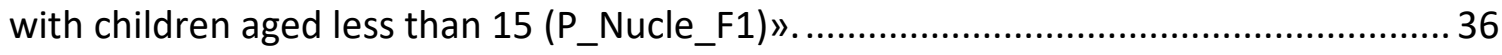

Figure 7 - Model SGWR 4 local standard errors of variable «percentage of family cores with children aged less than 15 (P_Nucle_F1)»................................................................. 37

Figure 8 - Model SGWR 4 local coefficient estimates of variable «percentage of owner-

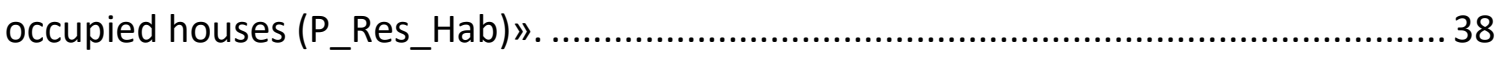

Figure 9 - Model SGWR 4 local standard errors of variable «percentage of owner-occupied

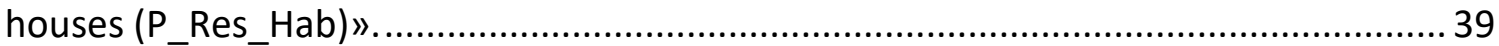




\section{LIST OF TABLES}

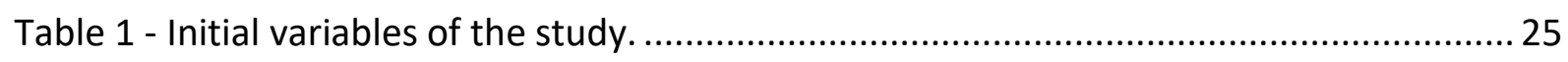

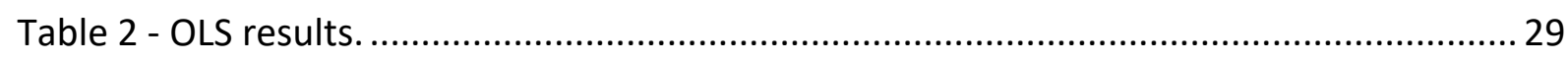

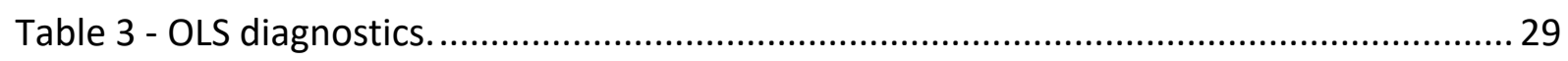

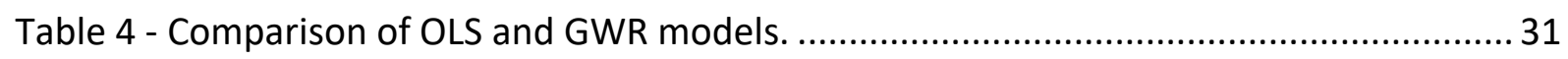

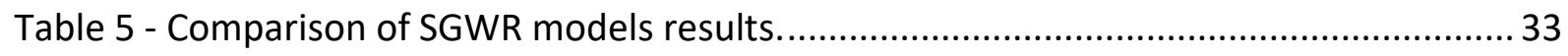

Table 6 - Model SGWR 4 global variables estimates.......................................................... 35 


\title{
LIST OF ABBREVIATIONS AND ACRONYMS
}

\author{
AICc Corrected Akaike Information Criterion \\ GWR Geographically Weighted Regression \\ OLS Ordinary Least Squares \\ SGWR Semiparametric Geographically Weighted Regression \\ VIF Variance Inflation Factor
}




\section{INTRODUCTION}

Voter turnout is a fundamental issue in any democracy (Douglas, 2013; M. N. Franklin, 2004; Ribeiro, Borba, \& da Silva, 2015) and, although it is not the only form of political participation, its importance is undeniable (Aldrich, 1993; Fornos, Power, \& Garand, 2004).

There have been a number of studies focusing on the causal determinants of voting behavior (Finkel, 1985; Geys, 2006; Ribeiro et al., 2015), concerning consolidated democracies but also newly democratic regimes (Fornos et al., 2004). Accordingly, it is important to identify, in Portugal, factors that influence voting.

\subsection{BACKGROUND}

Voter turnout is the total number of eligible voters who participate in an election. This is strongly related with other usual concept, the electoral absenteeism - the difference between the number of eligible voters and the number of participants ${ }^{1}$. According to the Constitution of the Portuguese Republic, every citizen older than eighteen years is eligible to vote, except in the cases identified by general law ${ }^{2}$. Voter registration is an automatic process since 2008 and, although voting is a civic duty, it is not mandatory.

The act of voting is directly related with the concept of democracy (Kostadinova \& Power, 2007) and provides the opportunity of political equality between citizens (Freire \& Magalhães, 2002). Voting strongly influences society, since political power is assigned through it (Freire \& Magalhães, 2002) and, in that sense, levels of turnout can provide information about the state of democracy (Franklin, 2004; Freire \& Magalhães, 2002).

Voter turnout varies across countries (Blais, 2006; Gallego, 2010; Jackman \& Miller, 1995) and over time (Blais, 2006). Empirical studies on this issue have revealed a set of variables that are related to voting and that are not necessarily common to all countries (Cancela \& Geys, 2016; Geys, 2006). Consensual is the fact that turnout has declined in most democracies in the last decades (Freire \& Magalhães, 2002; Gray \& Caul, 2000; Hooghe \& Kern, 2017), being Portugal no exception. The results of the legislative and presidential elections in 1999 and 2001, respectively, brought to light the issue, increasing the critical thinking and the debate (Freire \& Magalhães, 2002).

Voting is not yet well understood by politics scholars, despite its relevance (Aldrich, 1993). This author states that turnout is affected not only by election specific variables, but also by attitudinal and demographic variables, therefore it is difficult to explain who votes in an absolute way. In fact, as Feddersen (2004) notices, in large elections, the probability that an individual vote might change the election outcome is very small, which easily would explain why people do not vote when facing a

\footnotetext{
${ }^{1}$ Usually, in media and literature, voter turnout and absenteeism are expressed as percentages.

${ }^{2}$ According to Lei n. 0 14/79, from $16^{\text {th }}$ of May, the following are not granted active electoral capacity: a) Individuals judicially disabled due to a sentence imposed by a court of law; b) Individuals clearly and publicly known as mentally ill even where they are not judicially disabled, if they are committed in a psychiatric institution or if they are declared as such by a board of two doctors; c) Individuals who have been deprived of their political rights by a formal judicial decision.
} 
little obstacle. However, he also notices that other people make an effort to participate, which allows for build or reinforce an individual political attitude (Finkel, 1985).

Investigating persistence in voting turnout, Denny and Doyle (2009) try to understand the extent to which it is driven by habit, concluding that an individual who voted in the previous election is more likely to vote in the current election. Also, Plutzer (2002) focuses in habit forming, presenting a theory for the evolution of voter's political behavior. His analysis includes parental influence on initial turnout and growth, as well as the impact of life events on turnout growth.

Studies developed in several countries have been relating voter turnout to socioeconomic, political and institutional variables. Focusing on the effects of these sets of variables, Geys (2006) and Cancela and Geys (2016) review and assess empirical work where the dependent variable is voter turnout (or absenteeism). Blais (2006) also reviews studies in the field in order to verify which statements about the causes of cross-national variations in turnout are supported by empirical evidence. Despite the dominant view is that cross-national variations in turnout can be explained mostly by institutional factors (such as compulsory voting and rules designed to facilitate voting), Blais (2006) says that the understanding of the impact of institutions on turnout is unsteady and is conditioned by the presence of other factors, particularly those that differ from one election to another. In accordance, Hooghe and Kern (2017) state that institutional variables are not enough to explain the curve of the decline on turnout levels. Blais (2006) emphasizes the need to explore socioeconomic variables to achieve a better understanding of voter turnout. To understand if the variables explored among the industrialized democracies are relevant to countries with emergent democracies, Fornos et al. (2004) and Ribeiro et al. (2015) analyze voter turnout in Latin America. Referring to the period between 1980 and 2000, the first authors find that political and institutional variables are more relevant than socioeconomic variables. More recently, using data from 2009, the latter conclude that both types of variables affect voter turnout in Latin America.

From the set of variables presented by literature, education, age, gender, marital status, home ownership and economic measures have been largely studied. Focusing on the impact of education, Gallego (2010) compares the level of unequal participation in advanced industrialized democracies, verifying that inequalities are present in countries where education and voting are strongly related. Plutzer (2002) emphasizes education attainment when considering changeable characteristics of individuals' life. He concludes that education has a significant effect on turnout and that this contribute extends and cumulates over individuals' lifetime. As demonstrates Huckfeldt and Sprague (1992), individuals with higher education attainment are more likely to vote, among the ones lying outside the boundaries of conventional party involvement. Yet considering the universe of independent voters, those who are informed are more likely to decide an election, since abstention by uninformed occurs at a level that balances out the votes of partisans (Feddersen \& Pesendorfer, 1996).

Schlozman, Burns, and Verba (1994) analyze gender differences concerning to several kinds of civic activity, concluding that men are in general more active in politics than women. Going further, they find gender inequalities in the resources that facilitate participation (time, money and civic skills), which reflect men and women's roles and experiences in family, workplace and society. The traditional gender gap, characterized by women being more conservative than men and less likely to participate in politics, is also examined by Inglehart and Norris (2000). Comparing sixty countries 
around the world, the authors concludes that women's electoral behavior have been changing and explore the role of structural and attitudinal factors behind this change.

The relationship between age and turnout has been emphasized through a life cycle explanation, which relates low youth turnout with the presence of personal worries specific of this life period. Hence, in this scenario, participation increases with growth and the adoption of typical adult roles (Highton \& Wolfinger, 2001). An opposite explanation concerning age, commonly named generational effect, considers that low turnout is a permanent characteristic of a whole generation that does not change with experience and integration (Blais, Gidengil, Nevitte, \& Nadeau, 2004; Lyons \& Alexander, 2000; Wass, 2007).

Marriage and home ownership influence individuals participation in elections (Plutzer, 2002). Some studies identify positive influences of both factors (Denny \& Doyle, 2009; Squire, Wolfinger, \& Glass, 1987), since homeowners are more likely to feel connected to their community and, on the other hand, married people can share with the spouse the time and energy learning bureaucratic issues related to voting. Other studies present negative contributions of marriage (Highton \& Wolfinger, 2001; Stoker \& Jennings, 1995) and home ownership (Highton \& Wolfinger, 2001) to voter turnout.

Studies that focus on economic variables, with respect to electoral participation, use objective measures, such as unemployment rates, but also employs subjective perceptions of the economic situation, both inside and outside the country. Voter's response is influenced either by voter's personal economic expectations (Sanders, 2005), or by the opinions of those that live among (Pattie, Johnston, Schipper, \& Potts, 2015). Whatever the opinion about economic performance is, economic indicators explain much of the variance in government support, which can be related to its changeable nature (Lewis-Beck \& Stegmaier, 2000).

Concerning portuguese context, some of the mentioned socioeconomic variables have also been identified, namely age (Freire \& Magalhães, 2002; Magalhães, 2008), education (Freire \& Magalhães, 2002; Magalhães, 2008; Montargil, 1995) and economic measures (Freire \& Lobo, 2005; Freire \& Santana-Pereira, 2012; Gunther \& Montero, 2001).

Voter's contexts can help explaining turnout (Gallego, 2010), since the relation between socioeconomic status and absenteeism varies between countries (Nevitte, Blais, Gidengil, \& Nadeau, 2009). To some extent, the same idea can be thought to local contexts considering a single country. Most recently, voter's local contexts have been considered in the analysis of electoral participation, showing that political behavior is unevenly distributed across space (Cho \& Gimpel, 2009; Kavanagh, Sinnott, Fotheringham, \& Charlton, 2006; Mansley \& Demšar, 2015; Mota, 2019; Pattie et al., 2015; Taiwo \& Ahmed, 2015).

Kavanagh et al. (2006) analyze the influence of variables such as social class, education level and gender in election turnout using ordinary least squares (OLS), but the proposed models prove to be ineffective, pointing out the limitations of this technique when the relationships between variables varies across space. Going further, a technique that considers this variation was applied, improving results - geographically weighted regression (GWR). Also, in Nigeria, using GWR, it was possible to identify best predictors of voter apathy in presidential elections between 1999 and 2011 (Taiwo \& Ahmed, 2015), showing that this can be a useful tool to understand voting behavior. This idea is yet defended by Mansley and Demšar (2015) when analyzing turnout of a London's local election. 
Fotheringham, Brunsdon, and Charlton (2002) discuss GWR's utility, suggesting that sometimes in social sciences the measurement of a relationship depends on where the measurement is taken, so a global model can misrepresent reality. GWR attempts to capture this local variation, emphasizing differences across space. Given the expected variation of turnout between countries or within a single country, GWR seems to be suitable to the study of the phenomenon.

One extension of GWR is semiparametric weighted regression (SGWR), which includes both varying and fixed coefficients (Fotheringham et al., 2002; Nakaya, Fotheringham, Charlton, \& Brunsdon, 2009). Combining spatial stationarity and nonstationarity in the same model leads sometimes to a better model fit (Zhao et al., 2016), since the existence of some fixed coefficients can reduce the complexity of local relationships (Nakaya, 2015).

\subsection{StUdY RELEVANCE}

Low levels of voter turnout are an actual problem in Portugal. In the first legislative election, in 1976, the percentage of voters was $83.3 \%$, while this percentage was $55.9 \%$ in the last election, in October 2015 (PORDATA, 2015).

Before 1974, during the dictatorship, the role of elections was to confirm the continuity of the ruling party, giving to the international community the impression that Portugal was a democracy. After forty-one years, the April's Revolution, in 1974, enabled citizens to elect the deputies who would write down the Constitution of the Portuguese Republic. In that election, occurred on April 1975, participated $91.5 \%$ of voters (PORDATA, 2015). One year passed, the Constituent Assembly finished his work, with the approval of the Constitution, and the first legislative election took place.

Kostelka (2017) explains voter decline in new democracies, saying that it occurs in countries where the democratization process was driven by the opposition. The founding elections are highly mobilizing and after that turnout tends to decrease progressively, until it reaches the standard level.

Analyzing the results of all legislative elections (total of fifteen), it is a disturbing fact that, excepting for three cases, the percentage of voter turnout has always decreased, and that the lowest values of electoral participation were reached in the last three legislative elections.

The declining of turnout is usually considered to be unwelcome for democracy, because it is associated with a bad perceived state of the nation by citizens (M. N. Franklin, 2004). Freire and Magalhães (2002) say that it can indicate state stability and trust in people that apply to elections, but it also can indicate a lack of agreement between citizens' preferences and the available options. In the latter case, citizens are questioning the system itself and the political parties.

In Portugal, there is a general lack of interest concerning political issues (Canas, 2004). Attitudes related to political interest, identification to and reliance in political parties have been considered when trying to explain electoral participation in our country (Freire \& Magalhães, 2002). According to these authors, in the presence of variables that measure political engagement, these are the main reasons that contribute the most to explain electoral participation. However, according to Jalali (2003), studies about portuguese electoral behavior are still disperse and disorganized, despite Portugal being a consolidated democracy, with an experience comparable with countries as Italy, Germany or France. This makes hard the comparison with other different countries, and it is a barrier to understand the factors related to absenteeism. 
From Web of Science and ScienceDirect, with different keywords combinations (turnout, voting, electoral absenteeism, political absenteeism, political participation), the number of results including the term "Portugal» or "portuguese» is low (it varies between 0 and 30), whatever the terms are included in the title, abstract or author-specified keywords. Similarly, using the Open Access Portuguese Scientific Repository and the Nova University of Lisbon Repository, results include essentially sociological and political works using a qualitative methodology, which suggest that this issue has not been sufficiently addressed using quantitative methods in Portugal.

It seems quite evident that more research on the topic is needed within portuguese context. Understanding what influences this phenomenon gives the possibility of discussing it from an informed point of view and think about solutions based on evidence.

\subsection{Study OBjectives}

Looking at the lower levels of voter turnout in Portugal and thinking that voting is the foundational concept of a democratic structure (Douglas, 2013), it is important to understand the reasons behind absenteeism.

This work seeks to identify the most significant variables in explaining voter turnout in continental Portugal, within a group of objective variables measured in all country. Particularly, the study's objective includes finding out if the relationship between turnout and those variables varies across Portuguese regions.

It can even be said that, through this objective, a national contribution can be achieved: people can support their opinion about political participation in results that are real and rethink about institutional factors that can contribute to change the actual scenario, such as compulsory voting and voting facilitating conditions.

To achieve the study's objective, the following specific objectives are defined:

i) Identify sociodemographic variables that can be related to voter turnout in continental Portugal;

ii) Apply regression methods (OLS, GWR and SGWR) to study the relationship between those variables and voter turnout;

iii) Describe how the relationship between sociodemographic variables and voter turnout varies across the country. 


\section{LITERATURE REVIEW}

This chapter reviews the results of the empirical studies dedicated to voter turnout, focusing in the relationship between turnout and a set of variables, both indivual's characteristics and political and institutional factors. Particular attention is given to the studies regarding the portuguese context.

\subsection{RESULTS OF EMPIRICAL WORK AROUND THE WORLD}

\subsubsection{Sociodemographic variables}

Sociodemographic variables are important to understand voting behavior, however they have not been studied as deeply as they should (Blais, 2006). In the existing studies, different conclusions concerning the way sociodemographic variables influence turnout have been reached (Nevitte et al., 2009), which suggest that they are context depend and affected by the presence of other factors (Gallego, 2010).

\section{- Population size and population concentration}

Geys (2006) uses meta-analytic research procedures to assess the relationship between voter turnout and a number of explanatory variables identified in literature, through statistical analysis of the results of previous empirical studies. According to Geys (2006), the inclusion of the variable "population size» in some studies is related with the probability of someone's vote to be decisive to change the result of the election. Therefore, it is expected that, in some way, in larger communities, levels of voter turnout to be smaller. The author verifies that in a sample of 83 studies only 28 includes a measure of population size. Considering both the individual tests and the overall results of the studies, the author concludes that population size has negative effect on turnout, as hypothesized.

Referring to "population concentration» or "urbanization», Geys (2006) analyzes the results of 25 studies. The underlying hypothesis is that population concentration reduces turnout, since it promotes more fragile relationships between people living in the same area and reduces social responsibility and engagement. The results do not support the initial idea, suggesting that the effect of population concentration in turnout is weak.

Cancela and Geys (2016) extend the meta-analysis of Geys (2006) adding 120 recently published studies to the initial sample. Considering the same variables, the authors focus on the changes detected to the previous results of Geys (2006). Also, the authors distinguish determinants of voter turnout in national and local elections. The authors' findings are in accordance with the previous study of Geys (2006): while population size has a significant negative effect in turnout at both levels of election, there is no evidence regarding the influence of population concentration. Contrary, Mansley and Demšar (2015) find that population density exhibits a positive relationship with turnout in global regression, and mostly positive in local regression. The authors use sociodemographic census data to explain 2012 London mayoral election trough GWR and find local variations in electoral process.

Fornos et al. (2004) starts from the following hypothesis: since urbanization is often view as a national indicator of development, it is expected that urbanization increases turnout. They argue 
that, in urban areas, citizens are more exposed to information and have greater mobility, two factors that are usually associated with greater participation.

Based on results of previous research, Fornos et al. (2004) estimate models that explain variation in turnout due to institutional, socioeconomic and political variables, in Latin America countries from 1980 to 2000. In these models, the units of analysis are individual elections, which provides a total of 85 cases for parliamentary and 70 cases for presidential elections. Hence, for a given country and a given year, turnout is modeled as a function of independent variables measured at the time of each election. For socioeconomic variables, including urbanization, the coefficients are not statistically significant, thus Fornos et al. (2004) conclude that the relationship between socioeconomic environment and turnout in Latin America is fragile. The results for combined models, including institutional, socioeconomic and political process variables, show, once more, that socioeconomic variable are not significant predictors of turnout, both in legislative and presidential elections.

Also based on the idea that urbanization facilitates the spread of information, this variable is included in the study of Kostadinova and Power (2007), which analyses the impact of several variables in turnout in Latin America and Eastern European Transitional Democracies from 1978 to 2003. Similarly to the study of Fornos et al. (2004), elections are the units of analysis, and the conclusions concerning urbanization agree with the ones from those authors: the estimated coefficients are not statistically significant, both considering all countries in the same regression and two separated regressions, one for each region. Although the nonsignificant result, Kostadinova and Power (2007) notice that there is a negative association between urbanization and electoral participation in Eastern Europe, which can be due to the ability of Communist successor parties to mobilize voters in rural areas.

\section{- Population stability and homeownership}

As reported by Geys (2006), to estimate the impact of population stability on turnout, empirical studies have used one of the following measures: population mobility (the percentage of the population that has moved), population growth (the difference between number of births and number of deaths) and homeownership (the percentage of owner-occupiers in the community). The analysis of the 24 studies that include one of these measures shows that, in general, there is a positive and statistically significant relationship between stability and turnout. The same conclusion is reached by Cancela and Geys (2016), when they expand the sample used by Geys (2006) with the studies published between 2002 and 2015.

Squire et al. (1987) notice that residential mobility depresses turnout, when they analyze the results of the general election in United States, in 1980. For these authors, the turnout decrease that occurred in that election is, in some way, a consequence of the low turnout of those who had moved. For movers (those who moved within two years of election day), the requirement of a new registration is the main barrier to voting. To measure the effect of variables such as mobility, education and age on turnout, Squire et al. (1987) employ a probit analysis, since the dependent variable is dichotomous. They use two data sources: the 1980 NES, which is the standard source on voting behavior that includes questions about political attitudes, interest and behavior; and the CPS, which is a supplement of the Census Bureau that includes all the relevant demographic questions found ins NES, but is based on a bigger sample. Examining the relationship between mobility and turnout, the authors conclude that only $48 \%$ of people who had lived 2 years or less in the same 
place voted. Turnout is higher for people who had stayed 3 or more years in the same place, increasing as the number of years living in the same place increases, and it stabilizes when people live in the same place for more than 10 years - among these, $72 \%$ of people voted in the general election. Home ownership has a strong positive impact on turnout, which can be related, according to the authors, with the feeling of belonging to the community. The conclusions of Denny and Doyle (2009) referring to mobility agree with the results of Squire et al. (1987). Using data from birth to middle age, and applying different models, the authors start to find that a higher residential mobility is associated with a lower probability of voting between the ages of 23 and 33 . However, the impact of residential mobility between the ages of 23 and 33 is not significant when the model includes turnout in the previous election, which suggest the importance of persistence in voting behavior.

After confirm the impact of mobility on turnout, Squire et al. (1987) investigate if people with different characteristics respond the same way to the experience of mobility. Results show that mobility accentuates the impact of education and political interest on turnout. That is, the lower the level of education and political interest, the lower the turnout among recent movers. An increment in education level tends to increase the likelihood of voting, being people that have a college degree less affected by mobility than those who have not. As residential stability increases, these relationships become weaker. Concerning age, the effect of mobility in turnout is the same for all age groups - for those who recently moved, the probability of voting decreases approximately the same percentage points for younger and older people. Considering life events, although home ownership and marriage positively influences turnout, this influence is not strongly reinforced by mobility. In the case of home ownership, both renters and homeowners are affected by mobility in an identical degree and, in the case of marriage, the situation is similar.

The study of Plutzer (2002), which focuses in habit forming concerning political behavior, examines some life transitions that can occur between high school and first eligible election: attending college, being married, being a parent and moving across states. Again, the conclusion is that moving across is a statistically significant variable, with a negative impact on initial turnout. However, it does not achieve significance predicting turnout growth. Plutzer (2002) also examines events of the life cycle occurring after the first election that can help explaining turnout growth and concludes that home ownership is not a significant predictor. In the same direction, Highton and Wolfinger (2001) show that residential stability positively influences turnout, employing demographic data from the Current Population Surveys in United States. The voting rate is eleven percentage points higher for people who live in the same house for three or more years, compared to those who have moved within a year of election day. Going further and analyzing the transitions that are associated with young adulthood, the authors conclude that there is a low effect of home ownership for those living away from their parents, compared to the effect that is observed for older citizens.

Using data from 2002 general election in Ireland and from population census of the same year, Kavanagh et al. (2006) apply OLS technique to determine the degree of association between turnout and a number of demographic, socioeconomic and cultural factors. The correlation analysis suggests that residential mobility influences turnout, since there is a negative correlation between turnout and the percentage of people living at a different address the year before the general election. The correlation analysis also suggests that housing tenure is a significant predictor: correlation is negative when the house is rented, both for private and local authority, and is positive when there is owner occupancy, since no mortgage is associated. The study of Johnston et al. (2001) confirms the 
existence of a relationship between housing tenure and turnout. When they analyze the influence of neighborhood context on party choice at the 1997 general election in England and Wales, Johnston et al. (2001) find that respondents with distinct housing tenures respond differently: the larger the percentage of households who are local authority tenants in a neighborhood, the higher the Labour vote or abstaining, rather than Conservative vote.

Kavanagh et al. (2006) run four different regression models, including variables such as social class, unemployment, homeownership, percentage of males and percentage of the electorate aged 65 year and over. The authors conclude that all models, at varying degrees, are inefficient (the most robust one explains $56 \%$ of the variance in turnout) and suggest the existence of other variables not included in census. Moreover, they advert to the existence of local differences that OLS regression is not able to capture, since this method assumes that the relationship between variables does not change across space. Using GWR, a technique that accounts for the local variation, all the models previously tested perform better, with the most robust model explaining $72 \%$ of the variance. Kavanagh et al. (2006) illustrate this technique for the simplest model, including a single explanatory variable, social deprivation. They find an inverse relationship between social deprivation and general election turnout in some areas of the map, but a positive relationship in other areas and even regions where the relationship is weak and insignificant. The authors say that the relationship between turnout and variables such as class, education level and education also vary significantly across Ireland, which confirms the convenience of using GWR.

\section{- Marriage and children}

Marital status can influence the levels of participation, through changes in the circumstances in which people live or as a consequence of changes in their social networks. Particularly, marriage usually carries a number of changes in daily life, employment, and residence, but also represents an opportunity to learn from and influence each other (Stoker \& Jennings, 1995).

Squire et al. (1987) say that marriage positively influence turnout, since the effort to learn registration procedures and time spent to solve related questions can be made by only one spouse, although both couple members benefit. Denny and Doyle (2008) agree that being married increases the probability of voting, since married people have a clearer perception of their action impact on community. In the opposite side, the results of Highton and Wolfinger (2001) suggest that turnout of married couples is between one and two percentage points below that of singles, and the results of Stoker and Jennings (1995) show that the entry into marriage decreases one's likelihood of political involvement. Despite this result, Stoker and Jennings (1995) say that generalizations should not be done, and that it is important to consider a life-cycle dynamic regarding the influence of marriage in political participation - the effects of marriage are linked to its duration. Based on data provided from a national study developed with high school students and their parents, collected in 1965, 1973 and 1982, and including questions about the respondents' political participation, Stoker and Jennings (1995) reach a broader conclusion: marriage increases the probability that participation decisions are made together. The idea of the contagious effect of marriage is also referred by Timpone (1998), which says that married couples tend to vote or abstain together.

Denny \& Doyle (2009) obtain distinct results about marriage's influence, depending on if it concerns people's first election or subsequent elections. Applying probit regressions to estimate turnout in the 1987 and 1997 British general election, the authors find that being married and having children 
exerts a significant positive influence on turnout, both for models that include lagged turnout and the ones that do not. When estimating turnout in people's first election (the 1979 general election), they find that being married has little influence on the probability of voting and that having children has a significant but negative impact.

Plutzer (2002) verifies that marriage and having children have no significant effect on initial turnout, neither in predicting turnout growth. However, some years after, when people are older, marriage has a substantial positive impact on turnout growth. Even for those who were married the time of the first election and divorced after that, the growth rates are higher than for those who have never been married. According to Plutzer (2002), some years after the first election, having toddler or scholl-age children at home can have different effects on turnout growth. Since very young children need much time and energy, the effect on turnout is expected to be negative; otherwise, scholl-age children get parents engaged in community, which can increase political interest and knowledge and, therefore, influence turnout positively. The two measures used by Plutzer (2002) referring to the presence of toddler and scholl-age children do not achieve statistical significance, being the two estimates negative and similar in magnitude. Considering this similarity, the author replaces them by a single measure indicating the presence of children, which is significant on predicting turnout growth, negatively influencing it.

\section{- Education}

Education is closely related to political participation (Gallego, 2010), since more educated people tend to be more informed and critical, seeing voting as a possibility of change (Feddersen \& Pesendorfer, 1996). People with a low educational level faces more difficulties in understanding political questions, so they are more dependent on the guides given by parties and groups (Gallego, 2009). Associated with the costs, those difficulties can help explaining low voting rates of people poorly educated, a common characteristic of the three countries studied by Gallego (2009) Sweden, Norway and Germany. Also, the studies of Lyons and Alexander (2000) and of Blais et al. (2004) concerning the United States and Canada, respectively, show that voting rates are low among citizens with low levels of educational attainment. On the other hand, among political activities, voting is the more understandable, so it is the one that can easily engage people with few resources (Gallego, 2010).

A simple factor that influences voting is registration, being education the most important factor in the registration decision (Timpone, 1998). Nonetheless, Timpone (1998) notices that, in the universe of registered people, education does not distinguish those who vote from the ones who do not.

Feddersen and Pesendorfer (1996) demonstrate that information level, which can be related to education, influence participation and vote choice. Less informed voters tend to abstain, delegating responsibility to more informed voters. The study of Highton and Wolfinger (2001) also emphasizes the importance of information, particularly the one given by school communities. Leaving school is associated with a decreasing in turnout, which suggest an easier access to political information when people is attending school. Compared to non-students, the turnout of full-time and part-time college students is over 17 percentage points higher and 11 percentage points higher, respectively. Yet, Huckfeldt and Sprague (1992) conclude that individuals with a higher education attainment are more likely to vote, despite the education level of the community. These authors emphasize also the impact of the social structure for independent voters, saying that those who live in a community 
where educational level is higher are more likely to vote, regardless of their own educational levels. The effect of college attendance is highlighted by Plutzer (2002), who concludes that having attended college contributes to boost initial turnout. However, the effect of education in subsequent elections exceed the effect of college attendance on first election. In sum, education effect cumulates over lifetime and is independent of factors as holding a professional position or having a high income.

To analyze the impact on education on turnout, Denny and Doyle (2008) use two measures: the age at which the person left full-time education, and a variable that indicates if the person stay in school after the minimum school leaving age of 16. Data are provided from the 1958 National Child Development Study (NCDS), a longitudinal study of people living in Great Britain who were born in a specific date. Applying a model containing only educational and demographic explanatory variables, Denny and Doyle (2008) show that education influences turnout in a non-linear way. Remaining in school after the minimum school leaving age increases turnout by 3 percentage points, and each additional year of attendance increases the probability of voting by 0.3 percentage points. Adding to the previous model personality and cognitive ability measures reduces the coefficients of educational measures, while the remaining variables do not change much. According to the authors, this adjustment suggests that educational attainment should not be considered detached from other measures, at the risk of being misunderstood and, consequently, lead to inappropriate decisions. Further, given the significant impact that cognitive ability estimated at age 11 has on voter turnout, decisions intending to increase participation should concentrate on improving ability to read and interpret information, rather than on improving general educational attainment.

A different example that educational attainment should not be analyzed disregarding other measures is found in the study of Kavanagh et al. (2006) about general election in Ireland. Here, correlations between turnout and socioeconomic and demographic variables suggest that turnout increases in situations of educational disadvantage, and even the existence of an association between lower turnout and third level education. This association is confirmed by a multivariate regression, that is, third level education is negatively associated with turnout. However, Kavanagh et al. (2006) emphasizes that OLS technique seems to be ineffective in analyzing a relationship that varies significantly across space.

Based on the idea that inequalities in turnout are a consequence of the relationship between education and voting, Gallego (2010) creates a measure of inequality to be estimated and compared across advanced industrial democracies. Countries where education and voting are strongly related, exhibit large inequalities in turnout. For example, in countries such as the USA, the Czech Republic and Germany, the turnout rate is greater for those who have a high education level than for those who are poorly educated. On the other hand, countries where this relationship is not significant, do not exhibit inequalities in turnout, since people with distinct education levels have the same probability of voting. The impact of education on voting is stronger in preferential systems, in countries where registration is voluntary and when there is a high number of electoral parties. Hence, inequalities in turnout can be affected by contextual factors, since these can depress or encourage the propensity to vote in a heterogeneous way. It is the case of cognitive abilities required in the act of voting, which contribute to the gap in the turnout rates of different groups. 


\section{- Political knowledge and interest}

Analyzing data from eighteen Latin American countries, Ribeiro et al. (2015) conclude that the probability of voting is $20 \%$ higher for those who are interested in politics.

Since political interest and knowledge can positively influence turnout, Plutzer (2002) includes in his model two measures of psychological engagement in politics: a composite item of expressed interest in politics and the frequency of both newspaper and newsmagazine readership, and a political knowledge scale administered to students' parents. Both have significant effect on initial turnout, but it does not remain throughout lifetime.

Denny and Doyle (2008) suggest that the relationship between political interest and voter turnout may not be causal, since these variables are correlated. In fact, when excluding political interest from the models that they had created to explain turnout (containing educational and demographic variables, but also personality and cognitive ability measures), the authors obtain more plausible results.

\section{- Age}

When talking about turnout decline, authors have given emphasis to age (Gallego, 2009). The idea that people get involved with social phenomenon and become more participative, as they grow (Highton \& Wolfinger, 2001) has been recently complemented with the possibility of a generational effect (Wass, 2007).

Timpone (1998) studies the relationship between age and turnout, using a two-step approach: first, analyzing the procedure of registration; then, examining voting among the ones that are registered. He finds that age has a large influence in distinguishing registrants than non-registrants, being only overcome by education. Also, age has impact on turnout when considering only registered people. The author finds that the relationship between age and voting is nonlinear, but only if registered and non-registered people, are considered together in the same model. Hence, he concludes that the nonlinear relationship is driven by the probability of going to the pools among registrants.

Through a secondary analysis of survey data from nine presidential election in United States, Strate, Parrish, Elder, and Coit (1989) also analyze the effects of age in voting participation, arguing that, to understand political participation, some factors related to age must be considered into the analysis. So, the effect of age on voting can be indirectly explained by variables such as community attachment and civic competence. The authors conclude that a stronger community attachment, which tends to develop as people grow older, has a high impact on turnout. Moreover, civic competence increases with age and has the greatest impact on turnout, between all the variables considered. This connection between age and other variables, namely education, can be found in the study of Gallego (2009), concerning electoral participation over the last four decades in Norway, Sweden and Germany. Turnout decline is higher among young and poorly educated citizens in Norway and Sweden, but in Germany the effect of age is weaker. In this country, highly educated citizens tend to vote, even if they are young.

Investigating the finnish parliamentary elections between 1975 and 2003, Wass (2007) verifies the effect of a generational effect, since different values for the mean turnout are found when analyzing five generations of voters. The study of Lyons and Alexander (2000), using data from american 
presidential elections between 1952 and 1996, also shows a clear generational effect in turnout decrease: considering the twentieth century, the generation born before 1932 voted at a higher level than the generation born after. In the case of the finnish parliamentary elections, along with this generational effect, participation is related with age, both for older and younger generations (Wass, 2007), which is in accordance with the earlier studies. Among the youngest generations, turnout rises with age; for the oldest generations, turnout remains stable during the middle age and then decreases. The idea that turnout is higher for older citizens can also be found in the studies of Kavanagh et al. (2006) about general elections in Ireland, and of Ribeiro et al. (2015), about Latin American countries. In accordance, Romero and Fox (2016) conclude that young adults have voted at lower rates than other citizens, when examine turnout across California's counties.

\section{- Gender}

The relationship between gender and turnout is not consensual: some studies identify a positive correlation between turnout and the percentage of males living in an electoral division (Kavanagh et al., 2006), while others conclude that being male deceases the probability of voting (Denny \& Doyle, 2009). In the study of Denny and Doyle (2009), adding lagging turnout to individual characteristics, gender differences were not found concerning persistence in turnout.

Ribeiro et al. (2015) conclude that gender is not significant when explaining turnout in Latin-America countries. Instead, in Nigeria, differences in turnout across the country can be associated to the variations in the male population (Taiwo \& Ahmed, 2015).

Using data from a survey in United States, Schlozman et al. (1994) conclude that, considering the overall political activity, men are more active than women. Looking at specific issues, there are no gender differences in voting or attending a protest. However, statistically significant differences are found when analyzing membership or contributions to political organizations. Regarding the resources that can facilitate political participation (time, money and civic skills), the authors find gender differences, since women and men have distinct family, work and community experiences. Timpone (1998) observe that men and women behave differently, concerning electoral participation. After a moving, the main obstacle for women is registration, however, after overcoming this, the probability of voting is higher for women than for men.

\section{- Economic factors}

The impact of the economy on turnout has fairly been studied, and different results can been found (Blais, 2006). Several studies show that economic perceptions, as well as objective indicators, such as unemployment and inflation, can influence voters' decisions (Freire \& Lobo, 2005; Lewis-Beck \& Stegmaier, 2000; Sanders, 2000).

For example, in Canada, government support is higher if citizens have the perception that the incumbent party can deal with economic issues (Clarke, Scotto, \& Kornberg, 2011). More, British voters do not need to have a precise knowledge about economic facts to have an opinion about government's performance regarding economy (Sanders, 2000). According to the study of Sanders (2000) , whatever the economic knowledge is, voters recognize the impact of economy in their lives, so they can decide to support or punish the party in government when they come to vote. In a different study, where forecasting models are built to predict party support levels concerning the 
2005 general election on United Kingdom, Sanders (2005) suggest that personal economic expectations can influence voting. Referring to Greece, Nezi (2012) confirms that individual evaluations about the economy are associated with support or punishment to the incumbent party. In a period of crisis, which is the case of the 2009 election, Greek citizens tend to punish the party in government (Nezi, 2012), even though their economic perceptions are not completely accurate. In fact, in a study including Greece, Spain and Portugal, Freire and Lobo (2005) observe that, although economic perceptions do not always correspond to objective economic indicators, they can influence voting behavior.

Focusing on the countries where a major number of studies concerning economic voting have been carried out - United States, France, Britain and Denmark - Lewis-Beck and Stegmaier (2000) conclude that economic factors influence the government support. Besides the objective indicators, there is an economic subjective perception that occurs at the individual level and that is based on multiple factors and experiences. Even the variations between geographical units, regarding economic conditions, can influence the individual probability of voting (Bartle, Birch, \& Skirmuntt, 2017). These authors show that higher variations between geographical areas decreases the probability of voting, whereas economic heterogeneity within geographical areas increases that probability. When considering the two effects together, the overall impact is negative, meaning that the differences between units overcome the similarities within units.

Differently from the authors that find some impact of economic factors on turnout, Fornos et al. (2004) concludes that socioeconomic variables, such as per capita gross intern product (GDP), have a small effect on turnout, being the phenomenon largely influenced by institutional and political variables in Latin American countries. Kostadinova \& Power (2007) confirm the conclusion of Fornos et al. (2004) for Latin American countries, but find a positive significant effect of GDP on voter turnout in Eastern Europe. More recently, also regarding Latin American countries, Ribeiro et al. (2015) find that voter apathy is positively related with GDP, which suggests that a more comfortable economic situation reduces the relevance of the voting as a changing mechanism, and shows that the impact of the economy changes over time, space and circumstances. In Nigeria, voter apathy is positively related with GDP (Taiwo \& Ahmed, 2015). Using GWR analysis, the authors verify that turnout is lower in the more economically powerful states and that voter apathy is higher when unemployment rates are lower, both results suggesting that economic development may negatively influence turnout. On the other hand, higher unemployment levels can be associated with lower turnout, according to the conclusions of Mansley and Demšar (2015), when examining London mayoral election trough GWR.

Cancela and Geys (2016) confirm that, overall, economic inequality has been the object of growing analysis, but conclude that its explanatory power concerning turnout appears to be limited.

\subsubsection{Institutional variables}

The electoral procedures settled in each country can influence voter turnout (Geys, 2006; Jackman, 1987; Jackman \& Miller, 1995). The studies of Jackman (1987) and Jackman and Miller (1995), based on industrialized democracies, highlight the impact of institutional factors and represent the baseline for other studies, since the models used can explain up to seventy-five percent of cross-national variation in turnout (Jackman, 1987; Jackman \& Miller, 1995). 
Although the general perception that institutional variables can explain turnout in a consistent way, its impact depends on the presence of other factors and needs to be explored (Blais, 2006). In accordance, Endersby and Krieckhaus (2008) confirm the importance of institutional factors, but also show its conditional nature. Finally, Dettrey and Schwindt-Bayer (2009), studying presidential democracies, conclude that institutional variables should be considered when analyzing turnout, together with political context and socioeconomic environment, since none of them can give an exhaustive understanding on their own.

\section{- Electoral system}

Electoral system might be related with voting (Blais, 2006; Geys, 2006; Ladner \& Milner, 1999), being proportional systems pointed out as the ones that boost political participation (Jackman, 1987; Ladner \& Milner, 1999; Lijphart, 1997).

Lijphart (1997), reviewing theoretical arguments and empirical studies concerning levels of voter turnout in several countries, states that proportional systems increase participation between 9 and 12 percentage points, and that proportional representation can be a solution for inequality of citizens' representation. Similarly, Geys (2006) concludes that more proportional systems are associated with higher turnout rates, a conclusion also reached by Cancela and Geys (2016) on their extended meta-analysis. This can be related with the potential impact that each vote can have in a proportional system (Ladner \& Milner, 1999), contrary to a disproportional one, where parties need to accumulate a high number of votes to guaranty representation and, therefore, voting is discouraged (Jackman, 1987).

While studies restricted to industrial democracies (Jackman \& Miller, 1995; Jackman, 1987) or postcommunist Europe countries (Kostadinova, 2003) corroborate the idea that proportional representation increases turnout, results concerning Latin America countries have not found consistent results. Kostadinova \& Power (2007) states that disproportionality is an important predictor but, on the other hand, Fornos, Power, \& Garand (2004) conclude that disproportionality has little effect on turnout. Endersby \& Krieckhaus (2008) extend the analyses to all democratic elections, for national parliaments from 1972 to 2000. They find that the relationship between electoral systems and voter turnout depends on the way turnout is measured: if only registered voters are considered, electoral system has a small or negligible effect on turnout; however, if all voting age people are considered, proportional systems increases turnout between five and six percentage points in several countries. The authors also find that turnout decreases as countries become less democratic, and that the decline is higher for those with proportional systems.

\section{- Compulsory voting}

Approximately twenty-nine states have adopted compulsory voting, including a quarter of democracies across the world (Birch \& Lodge, 2015). Compulsory voting laws are expected to increase turnout (Blais, 2006; Cancela \& Geys, 2016; Geys, 2006; Jackman, 1987), but there is no uniformity concerning penalties to those who don't vote, which can explain the lack of people's compliance (Jackman \& Miller, 1995).

Gray \& Caul (2000), referring to consolidate democracies, conclude that turnout is significantly higher where compulsory voting laws exist, conclusion that is extended to Latin America countries by 
Ribeiro et al. (2015). In accordance, Fornos et al. (2004) find that some institutional variables, including compulsory voting, have significant positive effects on voter turnout in Latin America. The authors combine, in a single model, institutional, socioeconomic and political variables, and test it for legislative and presidential elections from 1980 to 2000. In both cases - legislative and presidential elections - they find that turnout is higher in countries with mandatory voting, especially if there are sanctions associated. Kostadinova \& Power (2007), comparing Latin America countries with compulsory voting and Europe post-Communist countries, conclude that participation in founding elections is lower in Latin America. However, although it remains lower in subsequent elections, the difference tends to diminish over time, which suggest the positive effect of compulsory voting.

Birch \& Lodge (2015) propose that vote should be mandatory to all citizens in the first elections for which they are eligible. The authors consider that this can help to increase turnout rates, since it would lead politicians to come closer of young people, still contributing to their engagement in political issues.

\section{- Voting age and Registration requirements}

Since political participation increases with individuals' growth (Highton \& Wolfinger, 2001), it is expected that voting age influences turnout.

Using data from more than 300 democratic elections held in 91 different countries, between 1972 and 1995, Blais and Dobrzynska (1998) find that changing the voting age from twenty-one to eighteen produces a five points decline in turnout. Also, Franklin (2004), states that lowering the voting age has produced a turnout decline in most democracies. However, this conclusion is not in accordance with the study of Endersby and Krieckhaus (2008). The authors include minimum voting age in their models, considering both the percentage of registered voters and the percentage of voting age population, and find that that variable is not significant.

Election laws, particularly registration requirements, varies over time and across countries (Blais, 2006) and its existence may difficult or facilitate voting, influencing turnout rates (Geys, 2006). Geys (2006) says that rigid registration procedures contribute to decrease turnout, whereas automatic registration, existence of an "election day registration» and the absence of literacy and poll taxes have the contrary effect. In line with these results, Cancela and Geys (2016) add that the relation between voter registration procedures and turnout is stronger in national elections than in the local ones.

Concerning the effect of rules that facilitate voting, Blais (2006) considers that the knowledge is not extensive enough. Moreover, the author emphasizes the need of more accurate measures to understand which rules facilitate voting and how easy it is to apply them.

\section{- Concurrent elections}

Analyzing twenty-two studies that estimate the effect of concurrent elections in turnout, Geys (2006) verifies that it is statistically significant. Moreover, in 12 of the cases, turnout significantly increases, which can be related to the presence of more information and attention given to the issue, creating an aware and motivated electorate. The relation between concurrent elections and voter turnout is confirmed in the study of Cancela and Geys (2016), where it is also stated that the explanatory power of concurrent elections is higher in local elections. 
Fornos et al. (2004) also suggest that concurrent elections intensify levels of information and political events. Their investigation, confined to Latin America's countries, enhances the influence of this institutional variable, stating that concurrent elections generate higher levels of turnout in both presidential and legislative elections. Accordingly, Kostadinova and Power (2007) find that the impact of holding presidential elections in the same day that legislative elections occur is stronger in Latin America than in Eastern Europe, although it is statistically significant in both regions when separated regressions analyses are considered.

\subsubsection{Political variables}

One of the traditional approaches to explain differences in turnout across countries focus on the political process (Fornos et al., 2004; Kostadinova \& Power, 2007). Aspects such as the closeness of elections are related with people's perception that they can take part of the public and political life (Fornos et al., 2004; Geys, 2006).

\section{- Electoral competition}

Turnout can be affected by closeness (Blais, 2006), since people's perception about the potential utility of their vote increases (Aldrich, 1993; Cancela \& Geys, 2016; Geys, 2006). The results of Franklin (2004), when examined turnout in advanced industrial democracies, agree with the idea that narrow margins of victory increase participation.

Nevertheless, the results of Fornos et al. (2004) regarding Latin America suggest that closeness or electoral competition - measured as the difference in the vote share of the first placed party and the second placed party - does not have a systematic effect on turnout. Using the same measure, Kostadinova \& Power (2007) find that it does not capture any effects of closeness on voter participation. These authors suggest that the differences in results, compared with the ones obtained for advanced industrial democracies, can be related with the fact that in established democracies patterns of party competition are clearly defined, being voters able to recognize distances between parties. That would not be the case in transitional democracies, where party systems are fragmented and not so easy to understand to citizens. In accordance, they find that multipartyism decreases turnout in Eastern Europe: when the number of parties rises by one, the percentage of voters reduce 2.4 percentage points.

\section{- Multipartyism}

The idea that multipartyism is inversely related to voter turnout is suggest by Jackman (1987), which emphasizes the unpredictability of coalition formation and, hence, citizens' perception that their vote will not directly influence the choice of the government. Jackman and Miller (1995) evaluate this relationship in twenty-two democracies, including Greece, Portugal, and Spain and find the expected sign for all coefficient estimates, meaning that multipartyism decreases turnout.

Geys (2006) adverts that the effect of multypartyism or political fragmentation on turnout is not consensual. Reviewing twenty-two studies that test this effect, where seventy-five coefficient estimates are provided, the author notices that the results are clearly inconclusive. However, the non-consensual scenario described by Geys (2006) seems to be replaced by the idea that political fragmentation has, overall, little explanatory power concerning turnout (Cancela \& Geys, 2016). For 
example, Fornos et al. (2004) find that, in Latin America, multipartyism has little effect on turnout, both in legislative and presidential elections.

\section{- Campaign expenditures}

Campaign expenditures is other political factor that might have a positive effect on turnout rates, according to Geys (2006), especially because campaigns contribute to rise information levels and, consequently, increase the probability of voting. From twenty studies, which provide ninety-seven results, the author verifies that the effect of campaign expenditures on voter turnout is significant. In line with the previous analyses, Cancela \& Geys (2016) conclude that higher spending during electoral campaigns is related with higher levels of voting, in $83 \%$ of the studies, and that campaign expenditures is a stronger predictor in national compared to local elections.

\subsection{STUDIES CONCERNING THE PORTUGUESE CONTEXT}

The high levels of abstention in Portugal in the last decades has brought to the table questions related to citizens' participation (Freire \& Magalhães, 2002), enhancing the need for studies which address the reasons behind this phenomenon (Jalali, 2003).

Many of the studies concerning Portuguese context focus in party identification of citizens and the existence of social and religious divides (Jalali, 2003). However, it is also possible to identify some works including individual characteristics of citizens (Freire \& Magalhães, 2002; Magalhães, 2008; Viegas \& Faria, 2004). Particularly, the economic perspective of voting has been addressed by several authors (Duch \& Stevenson, 2006; Freire \& Lobo, 2005; Freire \& Santana-Pereira, 2012; Gunther \& Montero, 2001; Martins, 2010; Nunes, 2005), which is in accordance with the growing impact of economic factors found in other democracies (Freire, Lobo, \& Magalhães, 2004). Few studies are available referring to political and institutional variables; the ones existing are comparative studies between democracies where Portugal is included, and they have already been mentioned in the previous section.

\subsubsection{Sociodemographic variables}

Freire and Magalhães (2002) investigate the individual characteristics of citizens that abstain in legislative elections in Portugal and European Union countries, running logistic regressions with Eurobarometer data from 1989 and 1994. Age and identification with political parties are the factors that contribute the most to explain turnout, both in Portugal and European Union countries. People who abstain are younger than those who vote, and poorly identify themselves with political parties. The authors suggest that the impact of age is related with changes in lifestyle: as people get older, they tend to be more involved in community and to assume more familiar and professional responsibility. Other individual factors associated with turnout are found by Freire and Magalhães (2002) in Portugal and European Union countries: marriage and religious practice increase participation, but having a better income has the opposite effect on vote.

Performing logistic regression with data provided from two surveys regarding Portuguese legislative and presidential elections of 1999 and 2001, Freire and Magalhães (2002) find, again, the effect of age in explaining turnout: age is the only significant socioeconomic indicator that explains turnout, being participation levels lower among the younger. In accordance, the study of Martins (2010) regarding 2001 municipal and 2002 legislative elections shows that the presence of people aged 65 
years or more has a positive effect on turnout. Life experience and available time to dedicate to political issues are the reasons suggested by the author to explain this result. Even in European elections, age, political interest and habit are factors that influence the decision of voting (Nunes, 2005), which can be related to community engagement and social intervention. The study of Mota (2019) highlights the need of considering geographical variations when studying the association between age and turnout. Analyzing the abstention rate of 2013 municipal elections using a geographically weighted approach, the author finds that an older population contributes to a higher abstention rate in the northern districts, and that the opposite relation can be observed in the south.

Similarly to Freire and Magalhães (2002), Viegas and Faria (2004) perform logistic regressions to identify factors that explain abstention in 2002 Portuguese legislative elections, with data provided from a post-election survey. Agreeing with the previous studies, the model obtained show the effect of age in explaining abstention, being the younger the ones who abstain the most. Adding to the model variables related to political attitude - such as political interest and trust in political parties and related to perceptions of the economy and government performance, Viegas and Faria (2004) confirm the impact of age, but also find the impact of political attitude, highlighting the need to understand the voting disaffection of young citizens.

In a study concerning the 2005 legislative and the 2006 presidential elections in Portugal, Magalhães (2008) presents logistic models including variables that reflect individual characteristics of citizens and their engagement in community (age, educational attainment, political interest, identification with political parties, belonging to unions and associations), but also related to political information exposure. Data provide from surveys applied to a representative sample of the population after the mentioned elections. Magalhães (2008) finds that the probably of voting increases with age. Moreover, it is not a linear relationship, since probability increases until people reach 70 years old, slightly decreasing from there on. The author also finds that people who discuss politics with others tend to vote more, being more informed and involved in more participative social networks. After age, this last variable - belonging to a social network where everybody participates - is the one which easily distinguish a voter and a nonvoter. In fact, the difference in participation of individuals who belong to a social network with low participation and those who belongs to a social network with a high participation is 14 percentage points, a lot more than the impact found for the remain variables. Finally, be exposed to political information through television and radio, during the campaign, increases the probability of voting. However, concerning the exposure through press, none impact on voting is found (Magalhães, 2008).

The access and the ability to interpret information are negatively correlated with the percentage of people who abstain, according to Montargil (1995). The author uses data from 1991 population census and legislative election and analyzes the correlation between sociodemographic indicators and abstention values. Montargil (1995) concludes that religiosity can interfere in this relationship, since there is a tendency to have higher levels of abstention in regions with higher percentage of people that regularly attend church. Accordingly, Jalali (2003) says that religiosity can influence the party preferences of electorate, as well as social class, when analyzing Portuguese electoral behavior concerning political parties. However, the traditional social divides are getting weaker (M. N. Franklin, 1992), especially in European elections, where citizens tend to decide under particular conditions and contexts (Nunes, 2005). Martins (2010) confirms the effect of education in turnout. In his study, the negative sign of the tax of illiterate people shows that citizens with a lower education 
attainment tend to be less participative. However, in his geographical approach, Mota (2019) finds that the percentage of individuals with a higher education increases the abstention rate, especially in some interior districts - the author clarify that those higher estimates are not the more reliable, considering its standard errors.

Gender differences in political participation are analyzed by Baum and Espírito-Santo (2004). Referring to 1999 and 2002 legislative elections and 2001 municipal elections, no significant differences are found between men and women, concerning turnout results, being the results similar to the ones registered in other democracies. Differences are found concerning non-conventional participation, like taking part in public demonstrations or giving flyers, being women less participative. Exploring those differences, the authors conclude that education, political interest and age are the factors that contribute the most to explain participation. They are related to gender in the sense that, traditionally, men are favored over women in portuguese context.

The impact of economy on voting is investigated by Freire and Santana-Pereira (2012), using multinomial logistic models to analyze data from the legislative elections of 2002, 2005 and 2009. The dependent variable is a nominal variable concerning the party choices of the electors, and the independent variables includes evaluations of the national and household economy, as well as other social indicators such as church attendance and belonging to an Union.

Freire and Santana-Pereira (2012) conclude that a negative perception of the economy is related with a higher probability of abstain or vote to the opposite parties. When controlling the effect of the other explanatory variables, the authors confirm the hypothesis that the perception of national economy is stronger than the perception of household economy. In fact, in 2002 and 2009, the perception of the household economy loses its significance in explaining vote choice and, in 2005, this predictor only explains the choice between the incumbent party and the traditional left parties. The results of the 2009 stress the importance of economic perceptions on voting, since economic evaluations are the only relevant predictors, together with political interest and ideology (Freire \& Santana-Pereira, 2012). However, the explained variance decreases over the years, hence the authors conclude that the relevance of economic perceptions varies over time and suggest that it may be influenced by other factors (such as general political context or extrinsic factors like international crisis), agreeing with the results of Duch and Stevenson (2006). Regarding economic vote in 19 countries over two decades, Duch and Stevenson (2006) find that economy influences turnout, but also identify significant differences between countries and over time.

Freire and Lobo (2005) also analyzes the role of economy on voting using objective economic indicators and subjective perceptions. A multilevel model is applied to Eurobarometer data from 1985 to 1999, referring to Greece, Portugal and Spain. Overall, the authors conclude that, in the three countries, the impact of economic voting is bigger than social class, when it refers to choose between incumbent or opposition. In accordance, Gunther and Montero (2001) find that economic perceptions have a bigger impact than social class in explaining voting, both in Portugal and Spain, when analyzing voting in four southern European countries. This impact is especially strong in Portugal, where Freire and Lobo (2005) also find that economic perceptions are more important in explaining turnout than objective indicators.

Martins (2010) compares the results of legislative and local government elections in Portugal, trying to understand if the variables that explain it are the same for both cases, particularly the ones 
related to economic conditions. The data used in the study come from several official sources, like INE - Statistics Portugal, International Monetary Fund and Ministry of Labor and Social Solidarity. Several models are estimated using OLS and other methods with logistic transformation of the dependent variable (the ratio between number of votes and registered voters). Martins (2010) concludes that all economic variables are statistically significant in legislative elections, which shows that, overall, economy has impact on voting. Participation increases when economic conditions get worse, that is, higher values of unemployment or inflation motivates citizens to participate and, contrary, better salaries and positive economic growth reduce participation. The author suggests that social media have here an important role, since they quickly spread information in adverse situations, which leads people to feel afraid of difficulties, even if the situations are not already happening. In local government elections, participation seems to depend on the degree of gravity of individual economic conditions, and indicators of national economy do not influence participation at all. The author says that these results can be related to the fact that people attribute less responsibility to local government and to the minor focus given by social media to local economy. Nunes (2005) tries to understand how citizens' perceptions about economic conditions and government performance influence participation in 2004 European elections. The author finds that citizens who vote in opposition parties negatively evaluate the economic situation and the government performance. In the opposite side, citizens who vote for the incumbent party have a positive perception concerning economy and government efficiency.

Starting from a boarder concept of civic participation, including voter turnout rates but also data about the foundation of volunteer associations, volunteer fire brigades and not-for-profit organizations, Tavares and Carr (2013) focus on the size, concentration and growth of city populations to explain differences in participation. The effect of these three variables is revealed when population concentration and city growth are used to mediate the impact of population size on civic participation. Both concentration and city growth have a positive impact upon the mentioned relation, however the direct effect of city growth in civic participation is negative. The authors argue that civic participation requires social interactions and psychological attachment, but a fast city growth does not favor it. Voting is the measure that is expected to be less affected, since it is less dependent on those social interactions.

\subsubsection{Political and institutional variables}

Going further in the study of the characteristics of citizens that abstain in legislative elections in Europe, Freire and Magalhães (2002) join contextual factors to the individual ones. Hence, the logistic regressions using Eurobarometer data from 1989 and 1994 includes, in this case, information concerning compulsory voting, disproportionality in the electoral system, electoral competition (defined as the difference between the two most voted parties), union density (defined as the ratio between the number of people belonging to an Union and number of active population), among other factors. Results show that the increase of electoral competition, Union density or proportionality, as well as the presence of compulsory voting are all factors that decreases abstention. The results of Martins (2010), regarding electoral competition in local elections is in line with the study of Freire and Magalhães (2002). Martins (2010) also concludes that a higher political fragmentation (defined as the number of parties that concur in an election) affects negatively turnout, either in legislative or in local government elections. The author says that this result can 
suggest, from citizens' point of view, a lower probability of their vote being decisive, since is more likely that party coalitions arise.

Comparing the models using only individual factors with the ones using the contextual factors, Freire and Magalhães (2002) verify that the explained variance is not very different, which reveals that the contextual factors add relatively little information in explaining turnout. Yet, Freire and Magalhães (2002) run several linear multivariate regressions to explain the average rate of abstention in 18 European democracies, in the 1970s and 1990s. In the decade of the seventies, the most important factor in explaining the differences between countries is the degree of disproportionality, followed by compulsory voting. The impact of these factors disappears in the decade of the nineties, which suggest that participation in European countries has become less affected by institutional variations. 


\section{METHODOLOGY}

This chapter describes the main methodological options considered in this work. A quantitative design is taken, since the understanding of the phenomenon is based on empirical evidence. Moreover, sociodemographic indicators are chosen based on literature, being the relationship between those indicators and turnout analyzed in advanced, which is one of the characteristic of quantitative studies (Creswell, 2003). Another characteristic expressed by this author is the possibility of generalizations, also included here, since both sociodemographic indicators and electoral results are objective measures concerning all population.

Data and analysis are detailed along the following sections, while Figure 1 provides an overview of the methodological framework. After the data collection and pre-processing, the research was developed in three major stages. First, for exploratory purposes and to select a subset of potential explanatory variables, several ordinary least squares (OLS) models were estimated and different statistical tests and measures were used to diagnose them. Then, the variables included in the most robust OLS model were included in a geographically weighted regression (GWR) model. In this second stage, other GWR models with new variables were also investigated. Considering that the obtained results were not satisfactory, SGWR models were investigated in the third stage.

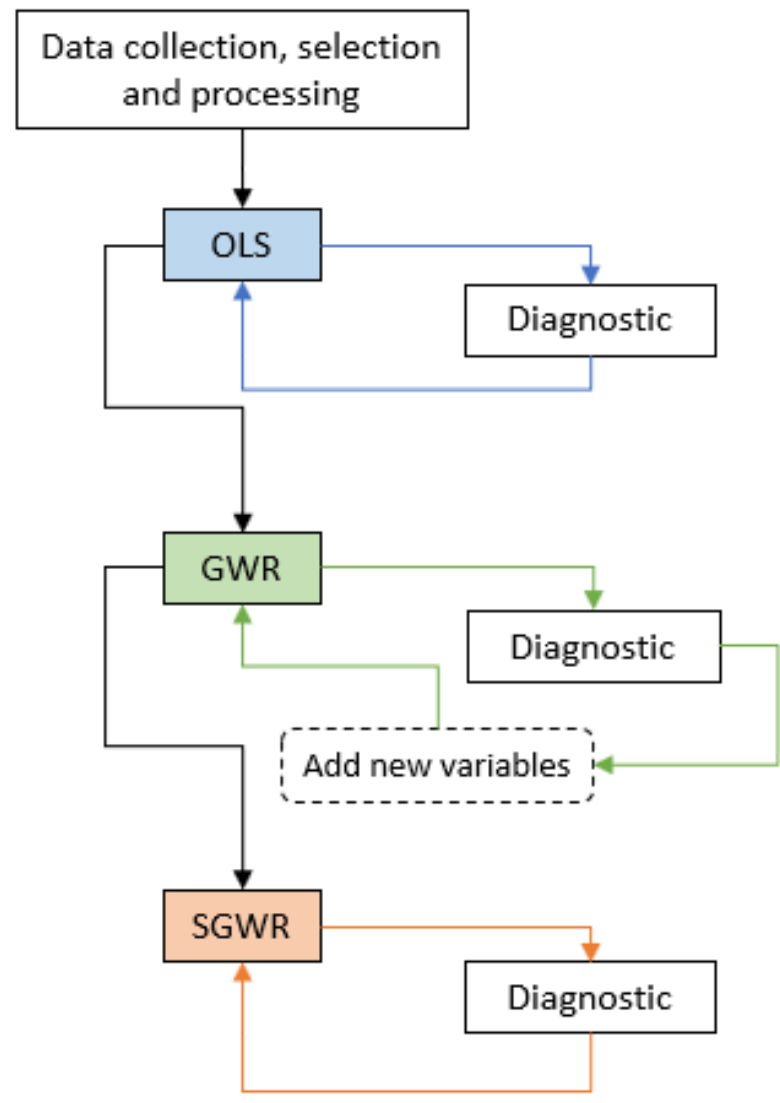

Figure 1 - Overview of the methodological framework. 


\subsection{DATA}

This work uses data from population census 2011 (INE, 2015). Since the last census are temporally close to the 2011 elections, the dependent variable is based on voter turnout in the same year (CNE, 2015). The dependent variable is the percentage of votes, computed as the ratio between the number of votes and the number of registered citizens. The recognized asymmetries that exist in Portuguese territory, for example between urban and rural areas, support the decision of working with percentages.

The choice of explanatory variables for voter turnout was based on the literature review aligned with available census data. The intention was to cover as much as possible the topics identified on literature and that are, at some extent, available on population census: population concentration and urbanization, age, gender, marriage and children, educational attainment, population stability and homeownership, unemployment.

From 25 variables chosen from census, new variables were drawn, in order to apply regression models. For population concentration and urbanization, the ratios were obtained using geographic areas. For instance, the percentage of classic families is the ratio between the number of families and the respective area. In the case of individual characteristics, such as age, the ratios were obtained using the total number of individuals living in that region. A detailed description of each of the variables is presented on Table 1.

\begin{tabular}{|l|l|l|}
\hline Variable name & \multicolumn{1}{|c|}{ Description } & \multicolumn{1}{|c|}{ Formula } \\
\hline P_Edificio & $\begin{array}{l}\text { Concentration of buildings mainly } \\
\text { residential }\end{array}$ & $\begin{array}{l}\text { Number of buildings mainly residential / } \\
\text { territory area }\end{array}$ \\
\hline P_Aloj & Concentration of familiar houses & Number of familiar houses / territory area \\
\hline P_Famili & Concentration of classic families & Number of classical families / territory area \\
\hline P_Individ & Concentration of residents & Number of residents / territory area \\
\hline P_Nucleos & Concentration of family cores & Number of family cores / territory area \\
\hline P_Nucle_F1 & $\begin{array}{l}\text { Percentage of family cores with } \\
\text { children aged less than } 15\end{array}$ & $\begin{array}{l}\text { Number of family cores with children aged } \\
\text { less than 15 / Number of family cores }\end{array}$ \\
\hline P_Nucle_F2 & $\begin{array}{l}\text { Percentage of family cores with } \\
\text { children aged more than 15 }\end{array}$ & $\begin{array}{l}\text { Number of family cores with children aged } \\
\text { more than 15 / Number of family cores }\end{array}$ \\
\hline P_Homens & Percentage of males & Number of males / Total number of residents \\
\hline P_Mulheres & Percentage of females & $\begin{array}{l}\text { Number of resident females / Total number of } \\
\text { residents }\end{array}$ \\
\hline P_Individi_3 & $\begin{array}{l}\text { Percentage of residents aged } \\
\text { between } 15 \text { and } 19\end{array}$ & $\begin{array}{l}\text { Number of residents aged between } 15 \text { and } 19 \\
\text { / Total number of residents }\end{array}$ \\
\hline P_Individi_4 & $\begin{array}{l}\text { Percentage of residents aged } \\
\text { between } 20 \text { and } 24\end{array}$ & $\begin{array}{l}\text { Number of residents aged between } 20 \text { and } 24 \\
\text { / Total number of residents }\end{array}$ \\
\hline P_Individi_5 & $\begin{array}{l}\text { Percentage of residents aged } \\
\text { between } 25 \text { and } 64\end{array}$ & $\begin{array}{l}\text { Number of residents aged between } 25 \text { and } 64 \\
\text { / Total number of residents }\end{array}$ \\
\hline
\end{tabular}




\begin{tabular}{|l|l|l|}
\hline P_Individi_6 & $\begin{array}{l}\text { Percentage of residents aged } \\
\text { more than 64 }\end{array}$ & $\begin{array}{l}\text { Number of residents aged more than 64 / } \\
\text { Total number of residents }\end{array}$ \\
\hline P_Indivi_Re & Percentage of iliterate residents & $\begin{array}{l}\text { Number of illiterate residents / Total number } \\
\text { of residents }\end{array}$ \\
\hline P_Ind_Res & $\begin{array}{l}\text { Percentage of residents with } \\
\text { completed } \text { 1 }^{\text {st }} \text { stage of basic } \\
\text { education }\end{array}$ & $\begin{array}{l}\text { Number of residents with completed } 1^{\text {st }} \text { stage } \\
\text { of basic education / Total number of residents }\end{array}$ \\
\hline P_Ind_Res1 & $\begin{array}{l}\text { Percentage of residents with } \\
\text { completed } 2^{\text {nd }} \text { stage of basic } \\
\text { education }\end{array}$ & $\begin{array}{l}\text { Number of residents with completed } 2^{\text {nd }} \text { stage } \\
\text { of basic education / Total number of residents }\end{array}$ \\
\hline P_Ind_Res2 & $\begin{array}{l}\text { Percentage of residents with } \\
\text { completed } 3^{\text {rd }} \text { stage of basic } \\
\text { education }\end{array}$ & $\begin{array}{l}\text { Number of residents with completed } 3^{\text {rd }} \text { stage } \\
\text { of basic education / Total number of residents }\end{array}$ \\
\hline P_Ind_Res3 & $\begin{array}{l}\text { Percentage of residents with } \\
\text { completed secondary education }\end{array}$ & $\begin{array}{l}\text { Number of residents with completed } \\
\text { secondary education / Total number of } \\
\text { residents }\end{array}$ \\
\hline P_Ind_Res4 & $\begin{array}{l}\text { Percentage of residents with post- } \\
\text { secondary education }\end{array}$ & $\begin{array}{l}\text { Number of residents with post-secondary } \\
\text { education / Total number of residents }\end{array}$ \\
\hline P_Ind_Res5 & Percentage of graduated residents & $\begin{array}{l}\text { Percentage of graduated residents / Total } \\
\text { number of residents }\end{array}$ \\
\hline P_Ind_Res6 & Percentage of employed residents & $\begin{array}{l}\text { Percentage of employed residents / Total } \\
\text { number of residents }\end{array}$ \\
\hline P_Famili1 & $\begin{array}{l}\text { Percentage of classic families } \\
\text { without unemployed }\end{array}$ & $\begin{array}{l}\text { Percentage of classic families without } \\
\text { unemployed / Total number of residents }\end{array}$ \\
\hline P_Ind_Res8 & $\begin{array}{l}\text { Percentage of residents who study } \\
\text { in the same municipality } \\
\text { in the same municipality }\end{array}$ & $\begin{array}{l}\text { Percentage of residents who study in the } \\
\text { same municipality / Total number of residents }\end{array}$ \\
\hline P_Res_Hab & $\begin{array}{l}\text { Percentage of owner-occupied } \\
\text { houses }\end{array}$ & $\begin{array}{l}\text { Percentage of residents who work in the same } \\
\text { municipality / Total number of residents } \\
\text { Number of familiar houses }\end{array}$ \\
\hline
\end{tabular}

Table 1 - Initial variables of the study.

In all analysis, municipality is the territorial unit. The use of aggregate level data for empirical analysis of voter turnout is suggested by Matsusaka (1995), instead of individual data, since individual idiosyncrasies can cancel each other. Also, Kavanagh et al. (2006) highlighted the potential of these type of data for spatial analysis of variations in the dependent variable. However, they point out the small number of variables available from census as an inherent limitation of using aggregate data, even though new ones can be drawn from available data, which have been done in this work. Moreover, the quality of results when studying turnout have been widely discussed, since electoral register can be outdated, for example containing citizens that are already dead or that have moved (Freire \& Magalhães, 2002). 


\subsection{ANALYSIS}

\subsubsection{Ordinary Least Squares}

Data analysis starts with the standard modelling approach, i.e. OLS modelling, whose parameter estimates show the "national picture» of the relationship between turnout and each of the explanatory variables. OLS is a widely used method of regression analysis, but it relies on a set of assumptions that spatial data often violates (ESRI, 2016; Fotheringham et al., 2002).

Using several combinations of explanatory variables, from the 25 constructed with the census data, OLS was continuously performed and diagnostic tools were applied. Diagnostic tools, available on software ArcGIS for Desktop (ArcMap 10.5), included:

(i) The analysis of the parameter estimates - the existence of multicollinearity and the significance of the predictors, respectively using Variance Inflation Factor (VIF) and ttests.

VIF values below the commonly used value of 7.5 generally indicate no multicollinearity between the model's explanatory variables (O'brien, 2007; Rosenshein, Scott, \& Pratt, 2011).

(ii) The analysis of the residuals - normality, homoscedasticity and independence, respectively using Jarque-Bera test, Koenker (BP) statistic and Global Moran's I statistic.

(iii) The use of measures of goodness of fit - Adjusted $R^{2}$ and Corrected Akaike Information Criterion (AICC).

The choice of AICC enables the comparison between models along all the analysis, considering its usefulness in local modeling contexts, the further step. According to Nakaya, Fotheringham, Brunsdon and Charlton (2005), AICc contains a more proper penalty for model complexity in a local modelling context, so it is less likely to lead to an over-parameterized model than conventional AIC.

OLS gives an idea about the key explanatory variables, however its results might not be representative of the situation happening in any particular region and may hide local differences important to explain voter turnout (Fotheringham et al., 2002). Considering the complexity of the relationship between voter turnout and the explanatory variables, it is expected that they can vary geographically. In addition, in Portuguese legislative elections, although deputies represent people at the national level, they are chosen through electoral circles. Thus, to a certain extent, there is a regional component in people's choice, so it can be worth to analyze voter turnout across Portuguese regions.

For each combination of variables, looking at model diagnosis, data show spatial nonstationarity, which confirms the idea that the use of a single coefficient describing the relationship between each explanatory variable and turnout is an oversimplification of the variability in local relationships (Cho \& Gimpel, 2009). Based on the comparison of the Adjusted $R^{2}$ and the AICC, the most robust of the OLS models was chosen, being its explanatory variables used to go deep into the analysis. 


\subsubsection{Geographically Weighted Regression}

Using the aforementioned data exhibiting spatial nonstationarity, a geographically weighted regression (GWR) was applied, since this method might be especially helpful with such data (Fotheringham et al., 2002). Considering the spatial variations that occur in the relationship between turnout and the explanatory variables, GWR provides an opportunity to better explain this phenomenon, since this technique tries to take into account spatially varying relationships, differently from the traditional global regression models (Fotheringham et al., 2002).

The parameter estimates obtained through OLS are global, and variations that might exist between the explanatory variables and the dependent variable are expressed in the error term. In GWR, the parameter estimates are local, since they are calculated for each point in the dataset. Here, the influence of the observations on the parameter estimates for each point is determined, i.e. weighted, by a function of the distance to that point. Consequently, observations close to a point have a greater influence on the parameter estimates for that point than observations which are further away from it (Fotheringham et al., 2002).

In this study, the spatial weighted function is an adaptive bi-square kernel, which adjusts over space, according to the number of points found, that is, the bandwidth of the kernel varies with the number of neighbors (Nakaya et al., 2016). The optimal bandwidth is automatically defined by the software, ArcGIS for Desktop (ArcMap 10.5), being the criterion chosen the minimum value of AICc.

Being flexible, the bandwidth of the spatial kernels is different for regression points located in urban or rural parts of the country, which is a relevant issue regarding voter turnout (Kavanagh et al., 2006). Since the data are densely clustered inside urban areas, the bandwidth is smaller in these areas, while it is larger in data scarce areas.

The use of the same measures of goodness of fit - Adjusted $R^{2}$ and AICC - allows a comparison between the final GWR model with the model obtained through OLS. For Fotheringham et al. (2002), AICc approach provides a useful tool for choosing models in GWR context, enabling the comparison between a GWR model and an OLS model and also the comparison between a number of competing GWR models. In both cases, the best model is the one with the smallest AICc value.

Also, the use of Global Moran's I statistic allows to assess the possible existence of spatial autocorrelation in the residuals of the GWR model. Evidence of spatial autocorrelation indicates that the GWR model might not be appropriate because important explanatory variables may be missing. According to Rosenshein and Scott (2012), spatial variables are the key to find a properly specified model when dealing with this kind of spatial data, such as explanatory variables related to distance. It is common to find different spatial patterns of the residuals in the more industrialized areas and in rural areas, attesting that the model is under or overpredicting turnout. Therefore, three new variables were drawn, related to the distance between each municipality and other places - distance to Lisbon or Oporto (the nearest), distance to the coast, distance to the district main city.

\subsubsection{Semiparametric Geographically Weighted Regression}

One important extension of GWR is the use of semiparametric models (Fotheringham et al., 2002), which mix terms of varying coefficients - influenced by location - and terms of global coefficients not affected by location (Nakaya et al., 2009; Nakaya et al., 2016). Therefore, the last modelling stage 
investigated the use of semiparametric geographically weighted regression (SGWR) models. SGWR is available on GWR 4.0, the software used from this point on, together with ArcGIS.

Considering that some sociodemographic indicators can be spatially stationary, it is suitable to use semiparametric models. Nakaya (2015) states that this technique enhances to reduce the complexity of local relationships, improving the interpretation of its geographical variations and the predictive performance of the model.

SGWR can be associated with model diagnosis to evaluate the geographical variability of the variables (Nakaya et al., 2009). In fact, besides the usual model comparison criteria, such as AICc, for different combinations of local and global variables, GWR 4.0 contains two techniques for automated variable selection, Local-to-Global (LtoG) and the reverse procedure, Global-to-Local (GtoL). LtoG variable selection routine makes a model comparison between the original GWR model, where all variables vary in space, with models where only one variable is constant. If GWR is the best model, the process stops. Otherwise it continues, now being the "original» model the one with a constant variable and all the others varying, and so on, until no improvements in the model can be obtained by fixing variables (Nakaya et al., 2009; Nakaya et al., 2016).

SGWR started with the variables that were used for GWR, including the distance variables drawn before. Independent variables standardization and LtoG variable selection routine were selected.

The options taken to GWR were repeat for SGWR, namely the use of an adaptive bi-square kernel and the finding of the optimal bandwidth based on AICc. Again, the comparison of GWR and SGWR models was based on AICC. 


\section{RESULTS}

\subsection{OLS AND VARIABLES SELECTION}

Starting with 25 variables chosen from the census, new variables were drawn. Combining these variables, several regressions were run, in order to find the subset with the highest explanatory power and to avoid multicollinearity issues.

The following variables were selected to go further into the analysis:

- Percentage of family cores with children aged less than 15 (P_Nucle_F1);

- Percentage of graduated residents (P_Ind_Res5);

- Percentage of classic families (P_Famili);

- Percentage of owner-occupied houses (P_Res_Hab).

Table 2 presents the results of the OLS model chosen, i.e. the one with the smallest AICc and the higher Adjusted R2, between a number of possible models verifying the diagnostic analysis.

\begin{tabular}{|l|l|l|l|}
\hline Variable & Coefficient & Robust Pr & VIF \\
\hline Intercept & 0.4521 & 0.0000 & ------- \\
\hline P_Nucle_F1 & 24.6126 & 0.0007 & 1.48 \\
\hline P_Ind_Res5 & 0.1446 & 0.0402 & 1.44 \\
\hline P_Famili & 0.2056 & 0.0110 & 1.61 \\
\hline P_Res_Hab & 0.1063 & 0.0055 & 1.36 \\
\hline
\end{tabular}

Table 2 - OLS results.

Results show that these predictors do not exhibit multicollinearity (VIF $<7.5$ ) and that they all are statistically significant, according to robust probabilities ( $p$-value $<0.05$ ). All the variables are positively associated with election turnout.

Observing OLS model diagnostic values (Table 3), it is evident the limited explanatory power associated with this model, with the four explanatory variables accounting for $16 \%$ of the variance of turnout. Nevertheless, the model has overall significance (Joint Wald statistic's p-value $<0.05$ ). Diagnostic results also show the normal distribution of the residuals ( $p$-value of Jarque-Bera test $>$ 0.05).

\begin{tabular}{|l|l|l|}
\hline Number of observations & 278 & \\
\hline \hline Adjusted $\mathbf{R}^{\mathbf{2}}$ & 0.16 & $\mathrm{p}$-value 0.0000 \\
\hline AICc & -860.14 & $\mathrm{p}$-value 0.0000 \\
\hline \hline Joint Wald Statistic & 77.17 & $\mathrm{p}$-value 0.1097 \\
\hline Koenker (BP) Statistic & 31.28 & $\mathrm{p}$-value 0.0000 \\
\hline Jarque-Bera Statistic & 4.42 & \\
\hline Globan Moran's I Statistic & 0.44 &
\end{tabular}

Table 3 - OLS diagnostics. 
However, there is evidence that residuals are heteroscedastic ( $p$-value of Koenker test $<0.05$ ), which indicates the presence of nonstationarity, and exhibit spatial autocorrelation ( $p$-value of value of Globan Moran's I test $<0.05$ ). These results thus justify the need for a spatial regression model. In accordance, in residuals map (Figure 2 ) it can be observed the existence of clusters of negative errors in the north, especially in the eastern part, and in the south interior (eastern Alentejo). Clusters of positive errors are found in the center, in the south coast and in Oporto metropolitan area.

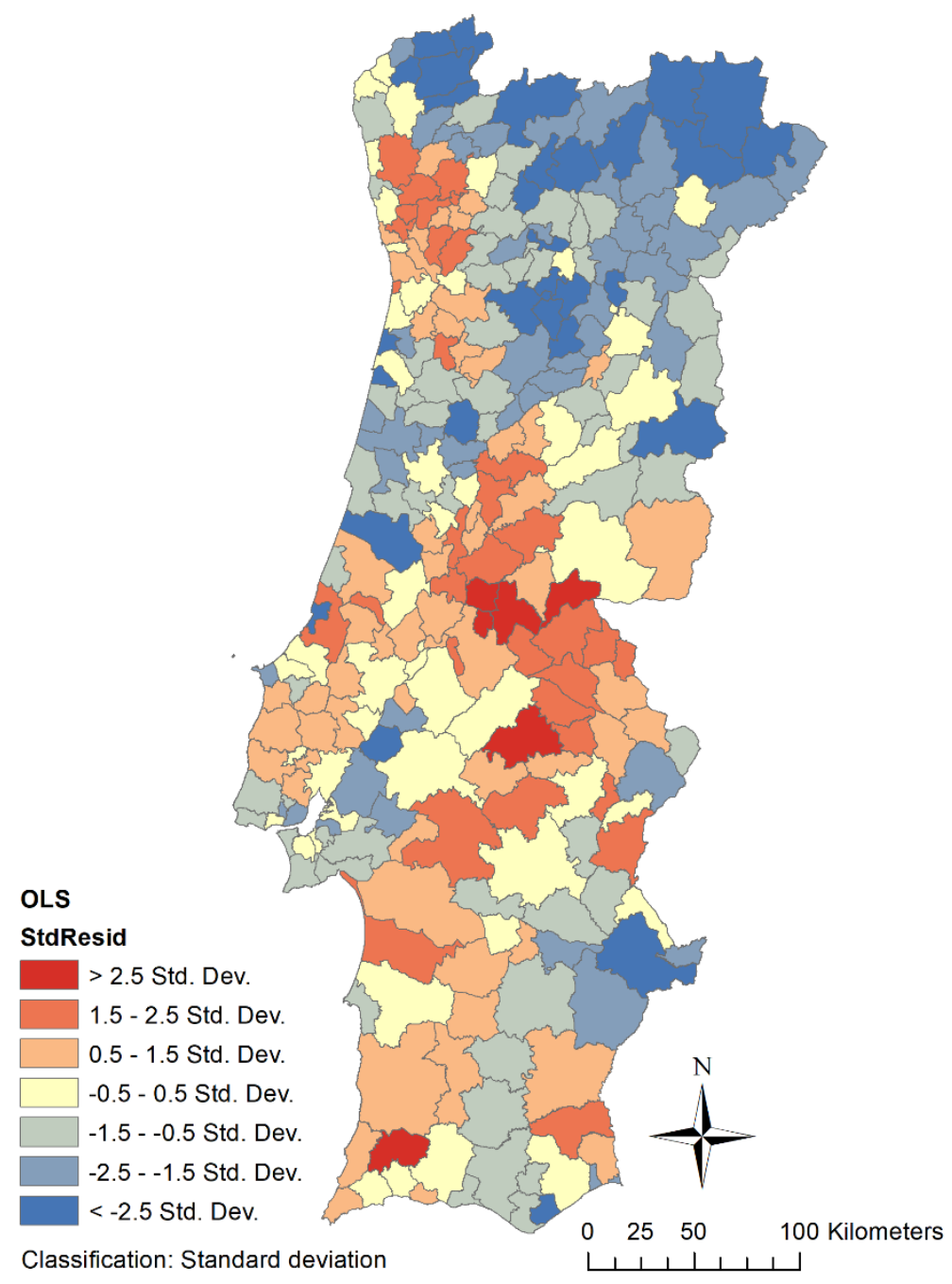

Figure 2 - OLS standard residuals.

In the presence of nonstationarity and spatial autocorrelation, GWR is a proper method to continue the exploratory analysis. Fotheringham et al. (2002) argue that GWR models are a suitable alternative to deal with these problems, when compared with other spatial regression models.

\subsection{GWR}

The four GWR models that were estimated included the predictors of the OLS model, and three of them included distance-based variables (Table 4):

- Distance to the district main city (Dsededist); 
- Distance to the cost (Distcost);

- Distance to Lisbon or Oporto - the nearest (DLXPorto).

The models obtained using GWR have a higher explanatory power than the OLS model (Table 4), since all of them have higher values of Adjusted $R^{2}$. There is also a reduction in the AICc value for all GWR models. In models GWR 1 and GWR 2, it is notable the improvement in the measures of goodness of fit. Contrary to the expected, the inclusion of a distance-related variable in the model does not result in an improvement in models' performance.

\begin{tabular}{|l|l|l|l|l|l|}
\cline { 2 - 6 } \multicolumn{1}{c|}{} & OLS & GWR 1 & GWR 2 & GWR 3 & GWR 4 \\
\hline Variables & $\begin{array}{l}\text { P_Nucle_F1 } \\
\text { P_Ind_Res5 } \\
\text { P_Famili } \\
\text { P_Res_Hab }\end{array}$ & $\begin{array}{l}\text { P_Nucle_F1 } \\
\text { P_Ind_Res5 } \\
\text { P_Famili } \\
\text { P_Res_Hab }\end{array}$ & $\begin{array}{l}\text { P_Nucle_F1 } \\
\text { P_Ind_Res5 } \\
\text { P_Famili } \\
\text { P_Res_Hab } \\
\text { Dsededist }\end{array}$ & $\begin{array}{l}\text { P_Nucle_F1 } \\
\text { P_Ind_Res5 } \\
\text { P_Famili } \\
\text { P_Res_Hab } \\
\text { Distcost }\end{array}$ & $\begin{array}{l}\text { P_Nucle_F1 } \\
\text { P_Ind_Res5 } \\
\text { P_Famili } \\
\text { P_Res_Hab } \\
\text { DLxPorto }\end{array}$ \\
\hline $\begin{array}{l}\text { Adjusted R } \\
\text { AICc }\end{array}$ & 0.16 & 0.58 & 0.57 & 0.47 & 0.27 \\
\hline $\begin{array}{l}\text { Global } \\
\text { Moran's I } \\
\text { statistic } \\
\text { (p-value) }\end{array}$ & $\begin{array}{l}0.44 \\
(0.0000)\end{array}$ & $\begin{array}{l}0.12 \\
(0.0000)\end{array}$ & $\begin{array}{l}0.13 \\
(0.0000)\end{array}$ & $\begin{array}{l}0.30 \\
(0.0000)\end{array}$ & $\begin{array}{l}0.43 \\
(0.0000)\end{array}$ \\
\hline
\end{tabular}

Table 4 - Comparison of OLS and GWR models.

The values of local $R^{2}$ vary between 0.03 and 0.73 in all territory, being stronger in the northwest and weaker in the centre. The condition number values are smaller than $\mathbf{3 0}$ for all the municipalities, hence there is no evidence of local multicollinearity among the explanatory variables.

However, global Moran's statistic of GWR models shows the presence of spatial autocorrelation. The residuals map of Model GWR 1 (Figure 3) confirms that residuals do not exhibit a random distribution pattern. Although the larger residuals are more dispersed about the study area, clusters of negative and positive errors can be found. Clusters of positive errors are still observed in the center, as well in municipalities near to Lisbon and Oporto. Also, clusters of negative values are still observed in the north and in the south interior. 


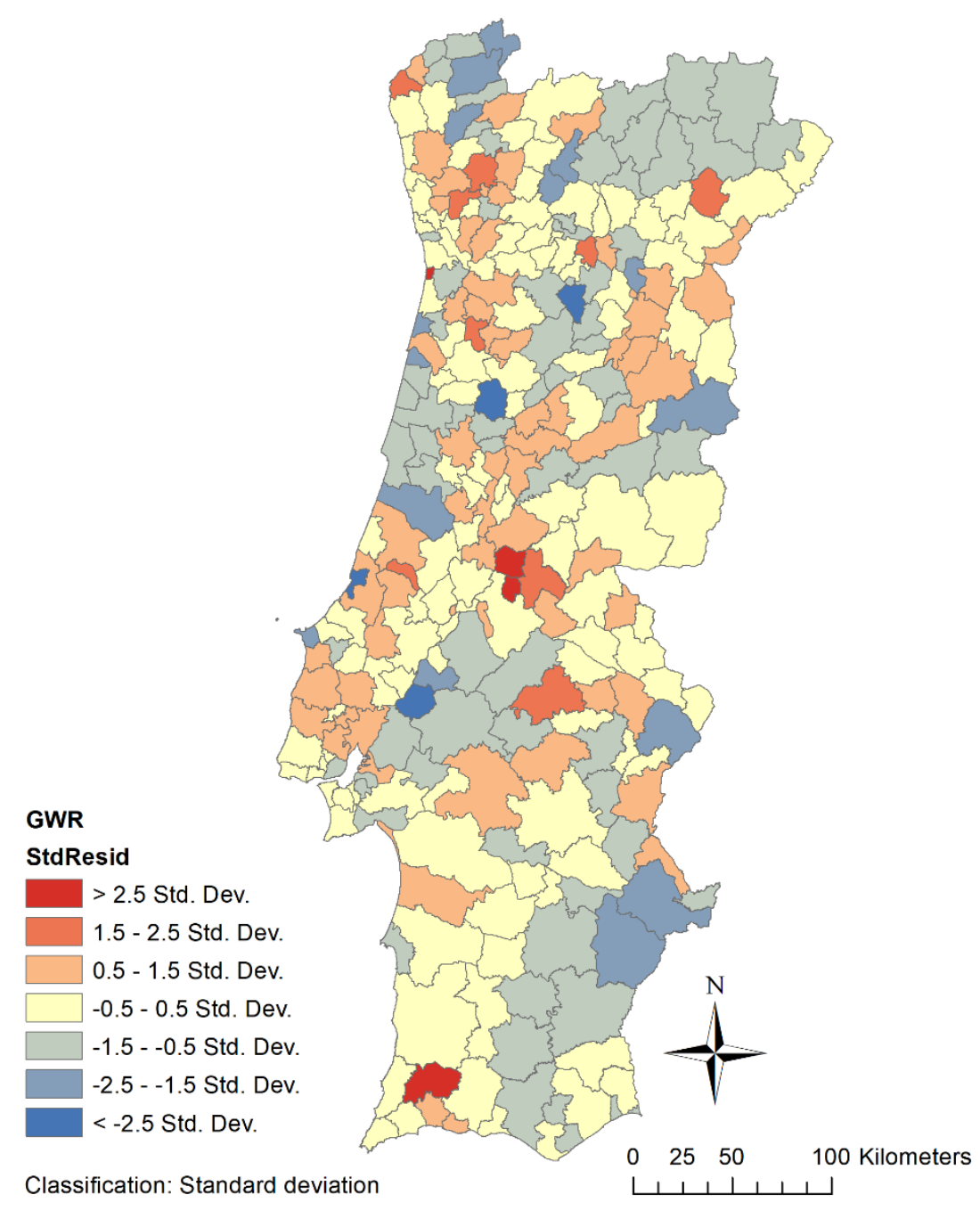

Figure 3 - Model GWR 1 standard residuals.

Having the ability of combining variables with coefficients that vary geographically and variables whose coefficients are constant all over the space, semiparametric models are more flexible and can reduce the complexities of local relationships (Nakaya, 2015). An extension of GWR was used, with the aim of testing semiparametric models.

\subsection{SGWR}

The explanatory power of the models obtained through SGWR increases, in comparison with the previous models. Models in Table 5 show higher values of Adjusted $\mathrm{R}^{2}$ than those in Table 4, and lower values of AICc. Here, the inclusion of a distance-related variable has a very positive contribution for model's performance. Model SGWR 2 attains the lowest AICc, closely followed by model SGWR 4. There is evidence of spatial autocorrelation in the residuals from all the models at the $5 \%$ significance level ( $p$-value of value of Globan Moran's I test $<0.05$ ), except from model SGWR 4. Hence, this model is considered the best one in this study. 


\begin{tabular}{|l|l|l|l|l|}
\cline { 2 - 5 } \multicolumn{1}{c|}{} & SGWR 1 & SGWR 2 & SGWR 3 & SGWR 4 \\
\hline Local Variables & $\begin{array}{l}\text { P_Nucle_F1 } \\
\text { P_Res_Hab }\end{array}$ & $\begin{array}{l}\text { P_Nucle_F1 } \\
\text { P_Res_Hab }\end{array}$ & $\begin{array}{l}\text { P_Nucle_F1 } \\
\text { P_Res_Hab }\end{array}$ & $\begin{array}{l}\text { P_Nucle_F1 } \\
\text { P_Res_Hab }\end{array}$ \\
\hline Global Variables & $\begin{array}{l}\text { P_Ind_Res5 } \\
\text { P_Famili }\end{array}$ & $\begin{array}{l}\text { P_Ind_Res5 } \\
\text { P_Famili } \\
\text { Dsededist }\end{array}$ & $\begin{array}{l}\text { P_Ind_Res5 } \\
\text { P_Famili } \\
\text { Distcost }\end{array}$ & $\begin{array}{l}\text { P_Ind_Res5 } \\
\text { P_Famili } \\
\text { DLxPorto }\end{array}$ \\
\hline Adjusted R & 0.66 & 0.67 & 0.66 & 0.67 \\
\hline AICc & -1084.79 & -1087.25 & -1082.96 & -1086.56 \\
\hline $\begin{array}{l}\text { Global Moran's I } \\
\text { statistic (p-value) }\end{array}$ & $\begin{array}{l}0.14 \\
(0.0000)\end{array}$ & $\begin{array}{l}0.06 \\
(0.0393)\end{array}$ & $\begin{array}{l}0.32 \\
(0.0000)\end{array}$ & $\begin{array}{l}0.05 \\
(0.0627)\end{array}$ \\
\hline
\end{tabular}

Table 5 - Comparison of SGWR models results.

The residuals from the SGWR models are less autocorrelated (Global Moran's I statistic equal to 0,05 for the chosen model) than those from the OLS model (Global Moran's I statistic equal to 0.44 ) and from GWR model (Global Moran's I statistic equal to 0.12 ), as expected. The reduction in the degree of spatial autocorrelation through SGWR can be seen if we compare the maps of the standard residuals from the three models (Figures 2, 3 and 4): the SGWR's residuals map exhibit a more random pattern than the others. 


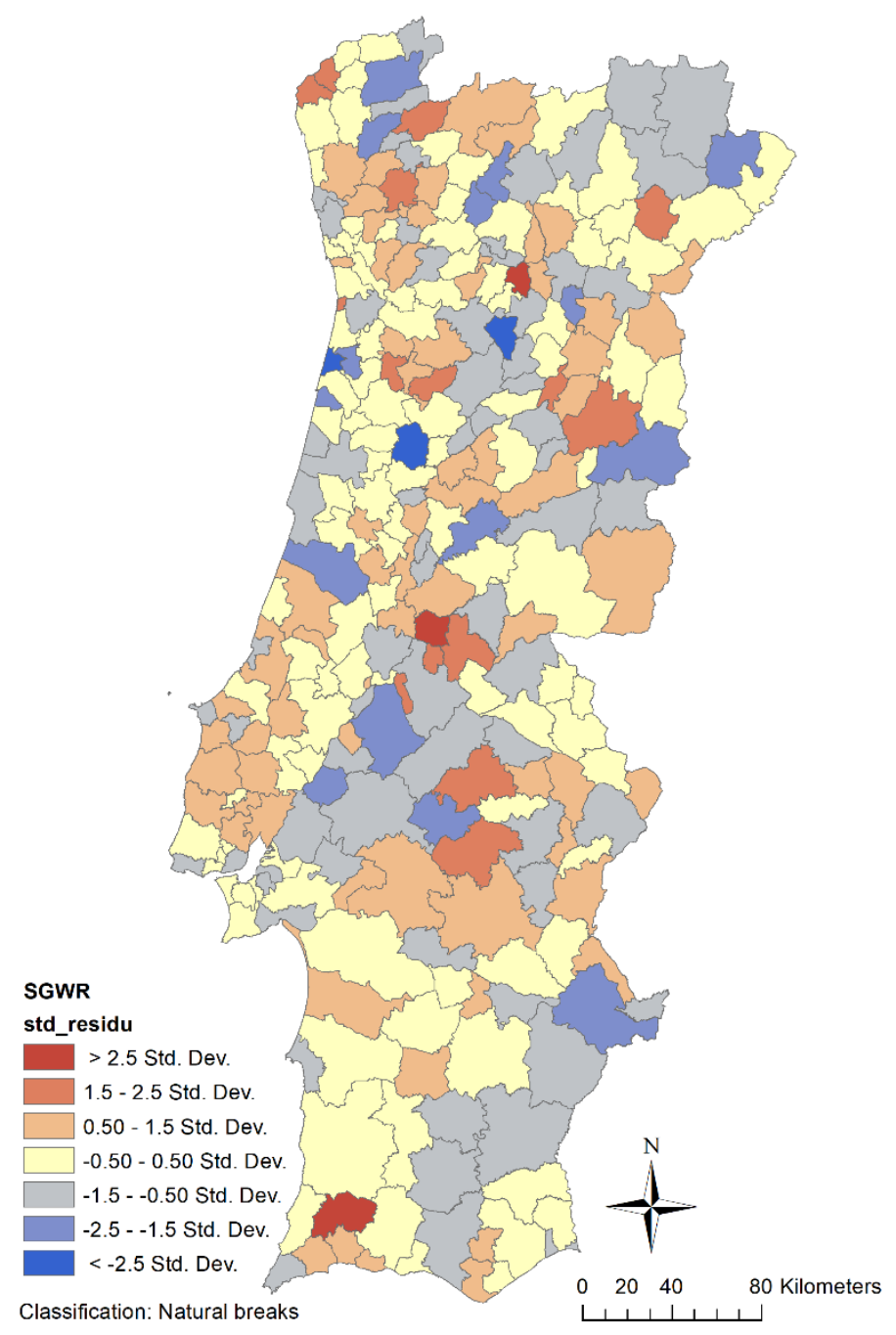

Figure 4 - Model SGWR 4 standard residuals.

The local $R^{2}$ values (Figure 5) highlight the geographical variability of some variables and suggest the misspecification of the model in the regions where those values are lower. The lowest values of local $\mathrm{R}^{2}$ are observed in the north interior (Trás-os-Montes e Alto Douro), in the south center (Ribatejo, Alentejo Central e Alto Alentejo) and in some municipalities of the south cost (Alentejo Litoral). 


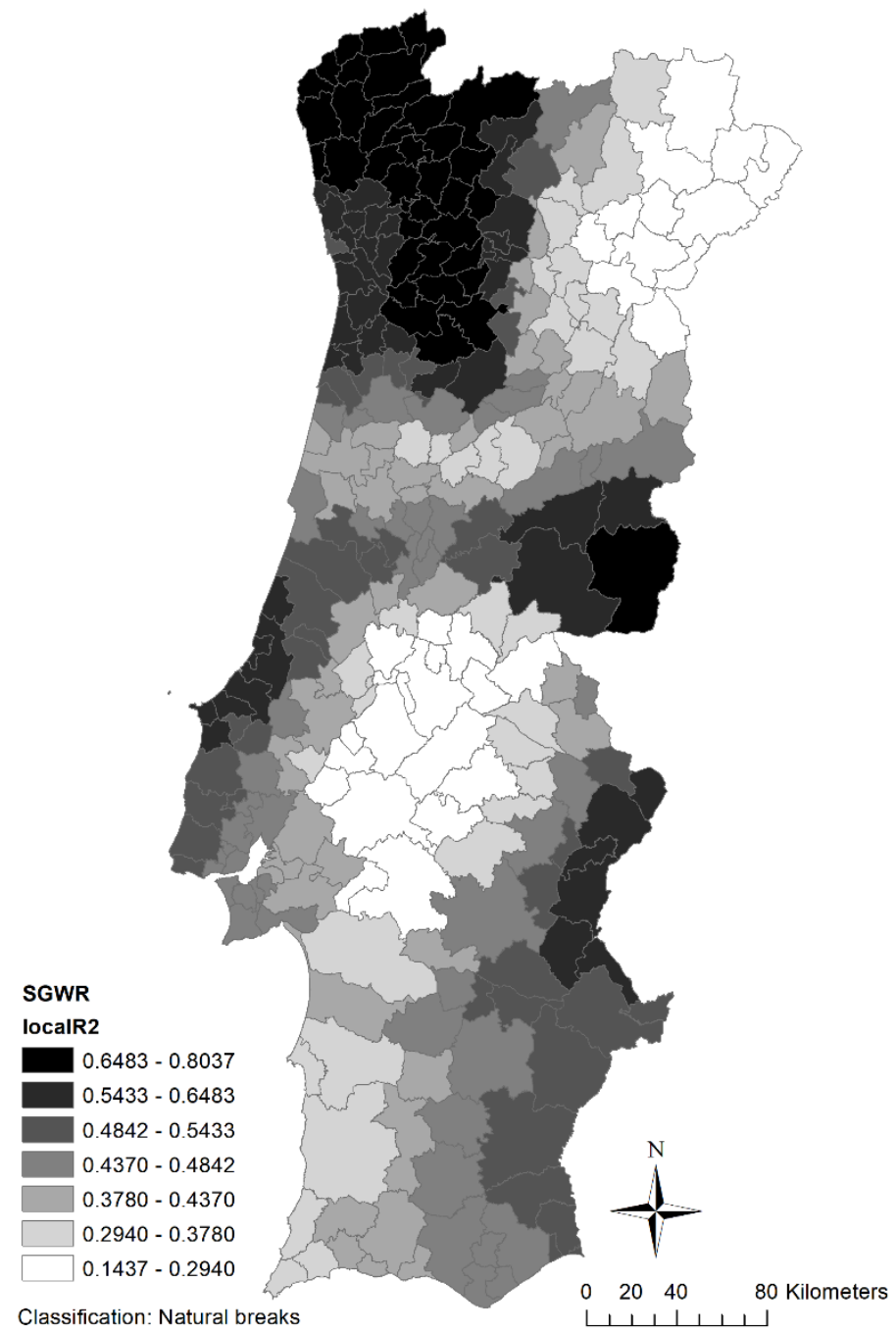

Figure 5 - Model SGWR 4 local R².

The maps of SGWR coefficients and standard errors (Figures 6 to 9) should be interpreted with caution. The map of the SGWR standard errors provides important information for conclusions drawn on the local relationships between the dependent variable and each predictor, because it allows identifying the areas where the model underpredicts and overpredicts voter turnout.

Percentage of graduated residents (P_Ind_Res5), percentage of classic families (P_Famili) and distance to Lisbon or Oporto - the nearest (DLxPorto) are global variables, i.e., the corresponding parameters do not vary in space. Table 6 shows that two of these variables, percentage of graduated residents (P_Ind_Res5) and percentage of classic families (P_Famili), are positively associated with turnout, while distance to Lisbon or Oporto - the nearest (DLXPorto) is negatively associated with turnout.

\begin{tabular}{|l|l|l|l|}
\hline Variable & Estimate & Standard Error & T (Estimate/SE) \\
\hline P_Ind_Res5 & 0.0131 & 0.0027 & 4.8043 \\
\hline P_Famili & 0.0018 & 0.0028 & 0.6477 \\
\hline DLxPorto & -0.0123 & 0.0048 & -2.5836 \\
\hline
\end{tabular}

Table 6 - Model SGWR 4 global variables estimates. 
Conversely, percentage of family cores with children aged less than 15 (P_Nucle_F1) and percentage of owner-occupied houses (P_Res_Hab) vary geographically. Figures 6 to 9 show the distribution of the coefficients and the distribution of the standard errors.

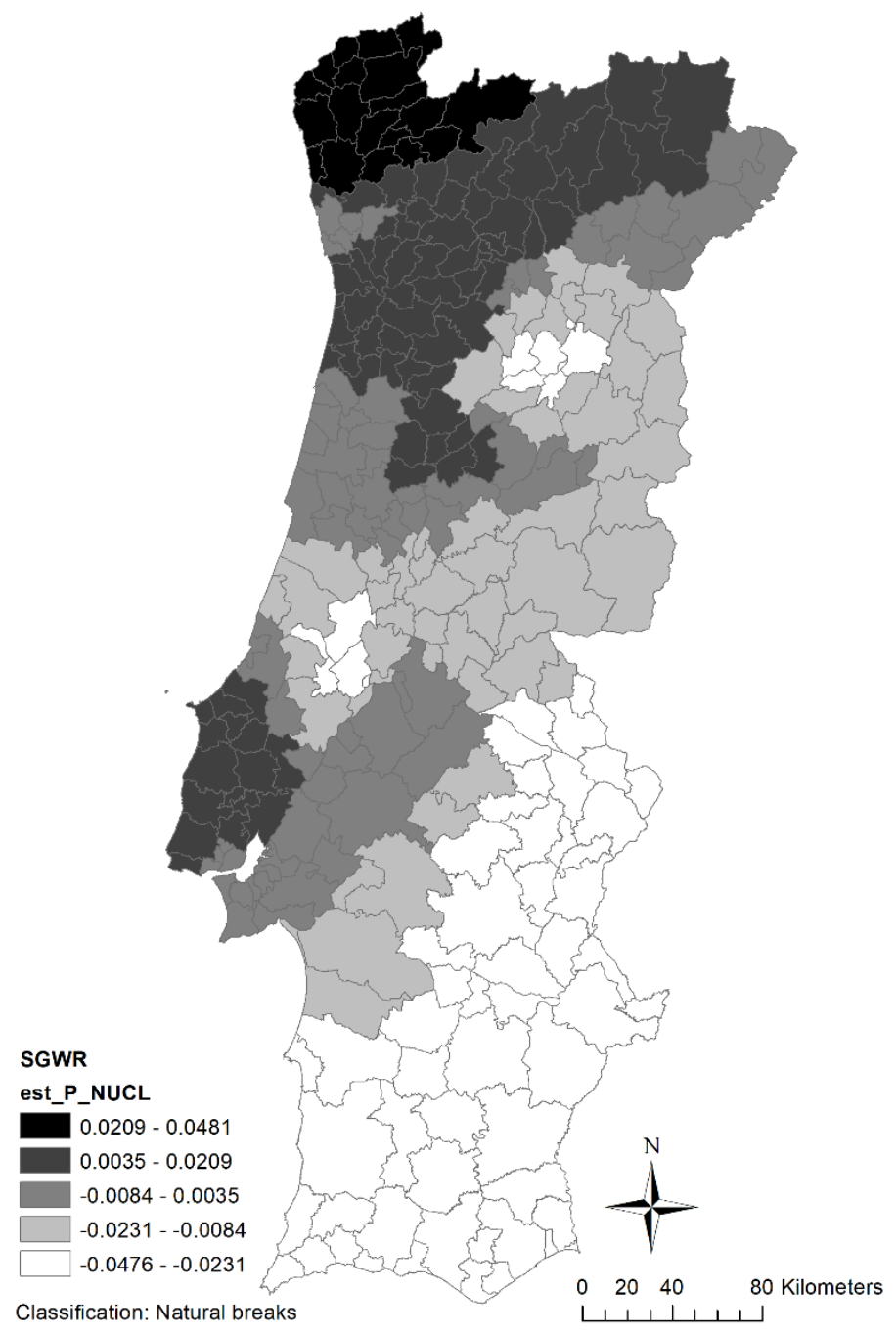

Figure 6 - Model SGWR 4 local coefficient estimates of variable «percentage of family cores with children aged less than 15 (P_Nucle_F1)». 


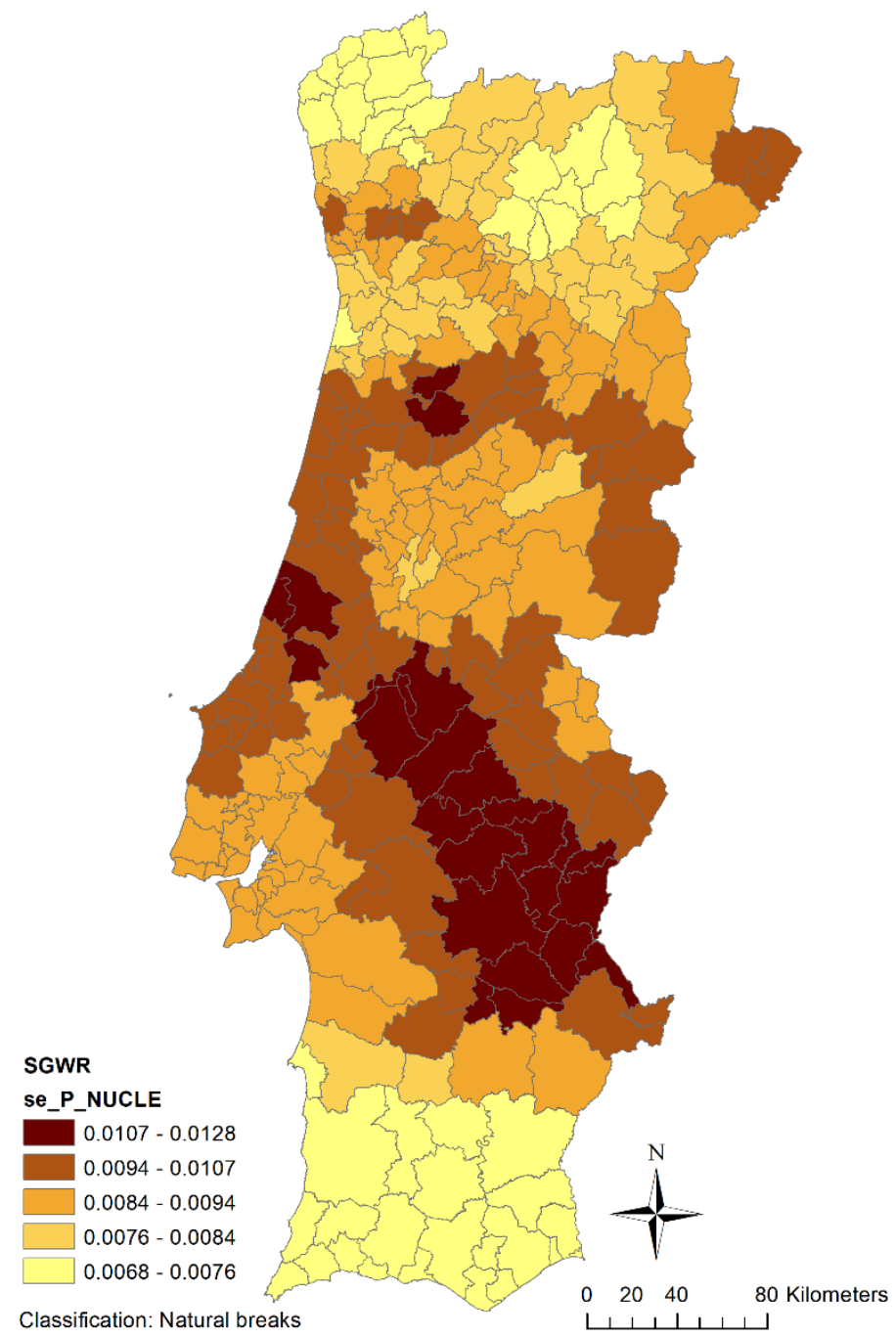

Figure 7 - Model SGWR 4 local standard errors of variable «percentage of family cores with children aged less than 15 (P_Nucle_F1)».

Figure 6 shows that the percentage of family cores having children aged less than 15 (P_Nucleo_F1) has a positive impact in the north, with exception for some municipalities close to Oporto (Vila do Conde, Trofa, Maia, Matosinhos, Santo Tirso) and for the main part of the municipalities of Bragança District. Moreover, its effect is positive in some municipalities of Lisbon metropolitan area (the ones located in the north side of Tejo river, with some exceptions - Lisbon city, Amadora, Oeiras, Odivelas) and in some municipalities of West Region, belonging to Leiria district but close to Lisbon. Contrary, the impact of having children with less than 15 is negative in the south, being stronger in its interior. This negative impact is also observed in the interior north, with exception for the municipalities located at north of Guarda district.

Regarding the distribution of the standard errors (Figure 7), the model brings more trust for the parameter estimates in the most southern regions (Algarve and Baixo Alentejo) and in the northern regions (Viana do Castelo, Vila Real and Bragança districts), with exception for some interior municipalities. Less trust is given to the parameter estimates in a central area (Alto Alentejo and Ribatejo). Nonetheless, the standard errors are close to zero in all municipalities, thus all coefficient estimates of this variable may be considered reliable. 


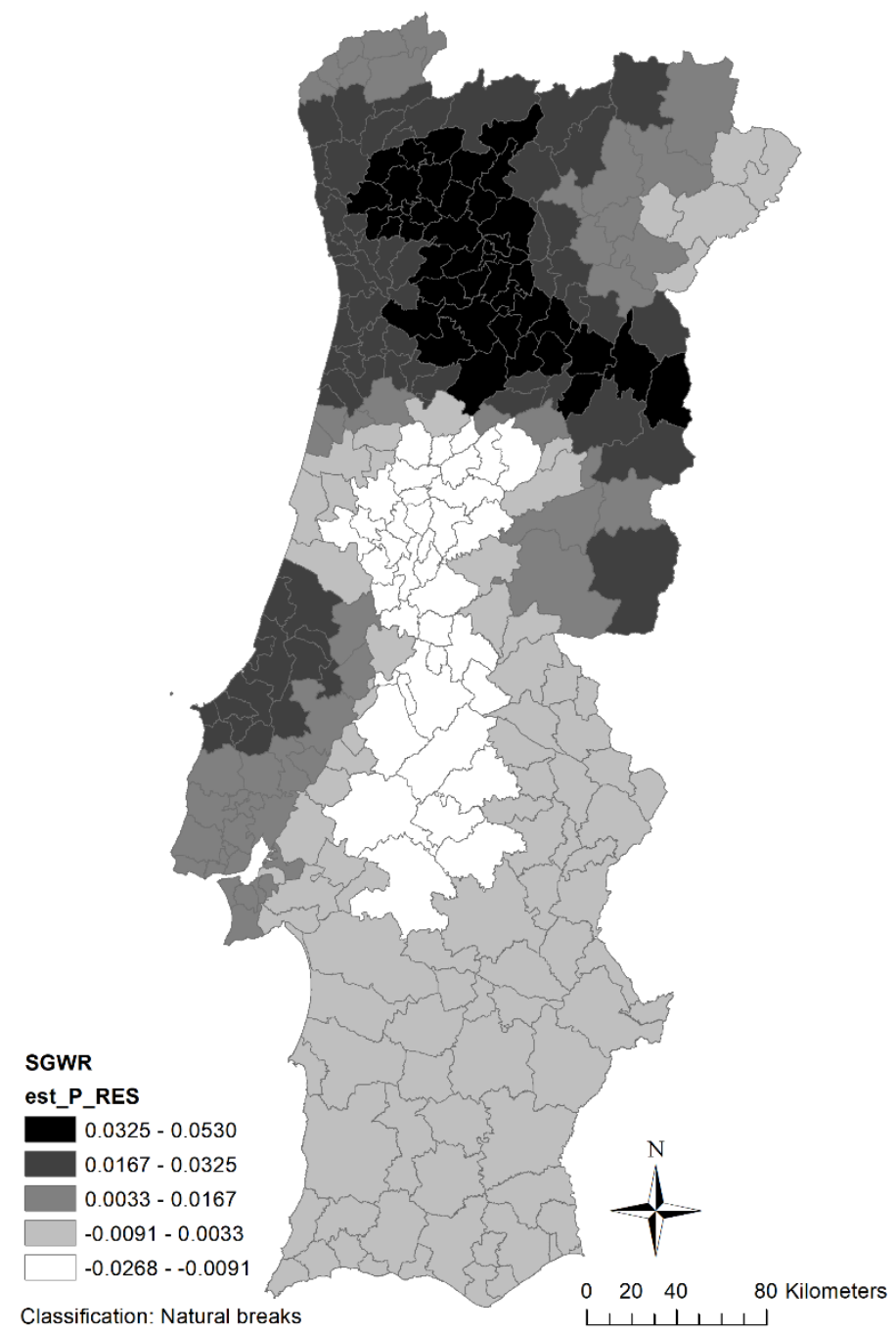

Figure 8 - Model SGWR 4 local coefficient estimates of variable «percentage of owner-occupied houses (P_Res_Hab)».

The percentage of owner-occupied houses (P_Res_Hab) is positively associated with turnout in almost all north region, according to Figure 8. Here, the highlight is a central area, including essentially municipalities of Braga, Porto, Viseu and Guarda districts. In the rest of the country, this positive influence is hardly notable, existing only in a coastal area which includes Lisbon district and other that are geographically close to Lisbon (Leiria and Santarém).

The effect of owner-occupied houses variable is close to zero in almost all south region. There is a central area, which includes essentially municipalities of Castelo Branco, Coimbra, Santarém, Évora and Portalegre districts, where this variable has a weak negative effect.

For this variable, Figure 9 shows that the model brings more trust for the parameter estimates in the most southern regions (Algarve and Baixo Alentejo), although the standard errors are close to zero in all municipalities, similarly to what happened for the percentage of family cores with children aged less than 15. The northeast part of the country, as well as the most interior municipalities in the north (from Castelo Branco, Guarda and Viseu districts) are the regions where the estimates are less reliable. Yet, the model has a low reliability in Alto Alentejo and Ribatejo regions (Évora, Portalegre and Santarém districts). 


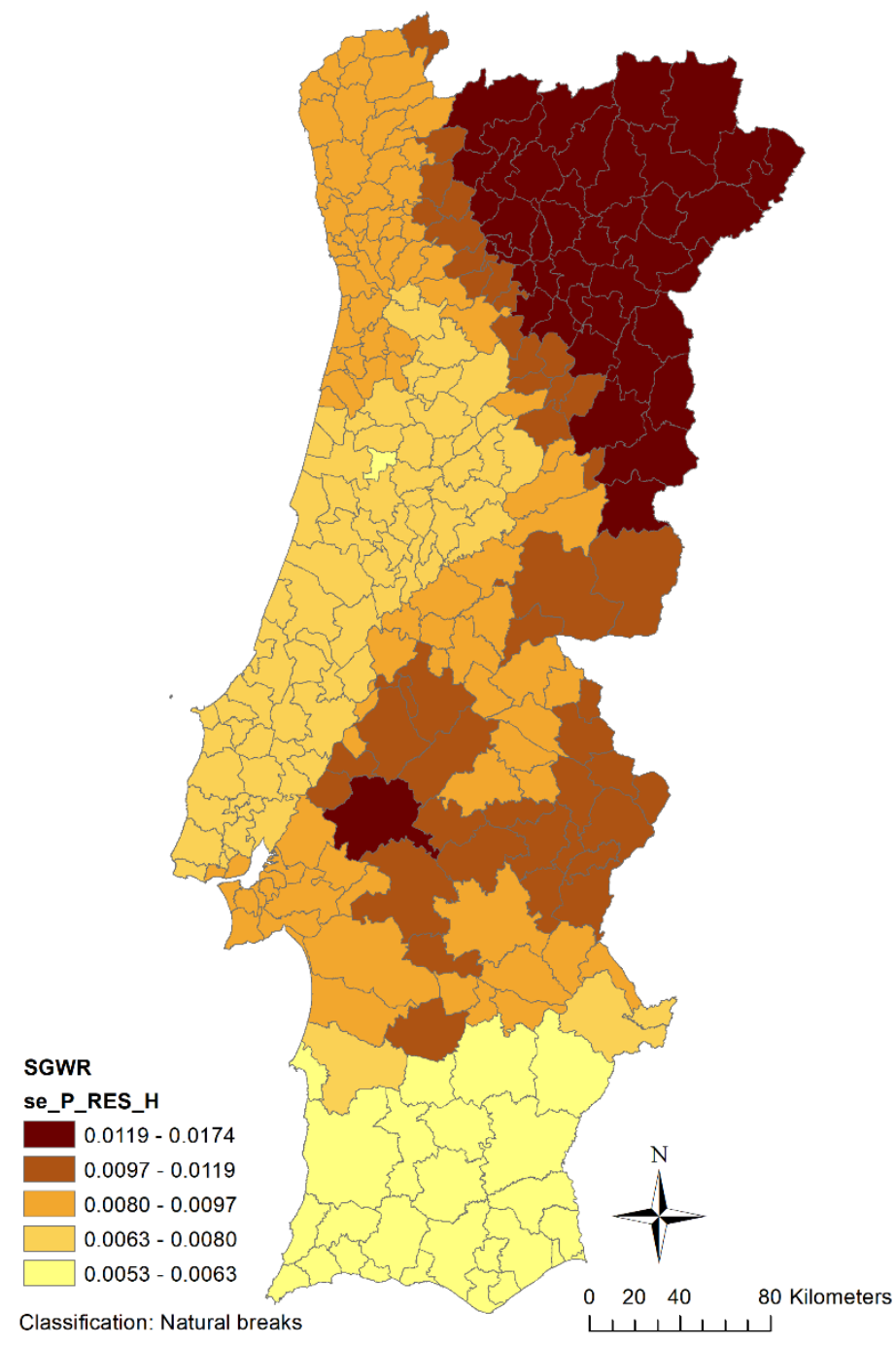

Figure 9 - Model SGWR 4 local standard errors of variable «percentage of owner-occupied houses (P_Res_Hab)». 


\section{CONCLUSION}

Voter turnout is a central concept in any democracy (Douglas, 2013), providing information about its state. Low levels of turnout are perceived as an indicator of the lack of interest in the democratic process (Franklin, 2004). In most democracies, including Portugal, the declining in turnout is notable (Freire \& Magalhães, 2002), which justifies the need for research addressing this issue.

This study investigates which socioeconomic variables affect voter turnout in continental Portugal and how the relationship between turnout and those variables varies over geographical space.

The analysis uses population census data and starts with conventional ordinary least squares regression. Geographically weighted regression is also applied, given the complexity of the relationship between voter turnout and the explanatory variables, which is expected to vary geographically, since it is a more spatially sensitive technique (Kavanagh et al., 2006). Finally, considering that the influence of some socioeconomic indicators on voting might not vary over space, a semiparametric geographic weighted regression approach is taken.

\subsection{DISCUSSION AND LIMITATIONS}

Results show that OLS regression is ineffective in analyzing the relationship between voter turnout and the sociodemographic indicators drawn from Census. Nevertheless, OLS regression is fundamental to identify possible predictors regarding voting, constituting an exploratory stage which drives the forward techniques. In fact, GWR regression starts with the same explanatory variables used in OLS regression. Evidence of spatial autocorrelation of the residuals leads to the inclusion of distance-based variables, which are commonly the key to find a properly specified model (Rosenshein \& Scott, 2012).

The increase of the adjusted $R^{2}$ value from the OLS model to the GWR model, together with the decrease of the AICc value, indicates that there is substantial spatial variation present in the socioeconomic variables that influence turnout. However, the presence of spatial autocorrelation in the distribution of the standard residuals remains from OLS to GWR model, suggesting the use of a mixed approach, i.e. a model including both varying and fixed coefficients (Fotheringham et al., 2002; Nakaya et al., 2009).

SGWR captures the spatial stationarity and nonstationarity to model the variables that explain voter turnout, and a better model fit is achieved with higher adjusted $R^{2}$ and lower AICc. In addition, SGWR standard residuals exhibit a more random pattern than residuals from the previous models, as observed in its maps and confirmed by Globan Moran's I Statistic. The presence of spatial variation was confirmed through the maps of the coefficients estimates, and its reliability was assessed through the maps of the standard errors coefficients.

The results obtained are now discussed, in the context of the expectations given by literature review.

Using OLS regression, the percentages of family cores with children aged less than 15 , graduated residents, classic families and owner-occupied houses are identified as possible significant predictors of voter turnout, all of them positively influencing the phenomenon. 
Earlier research finds that variables related to population stability (home ownership, residential mobility, residential stability) have impact on turnout (Denny \& Doyle, 2009; Highton \& Wolfinger, 2001; Plutzer, 2002; Squire et al., 1987), which is in accordance with the inclusion of the variable «percentage of owner-occupied houses» in the model. Given the existence of studies concluding that educational attainment is associated with voting rates (Blais et al., 2004; Gallego, 2009; Huckfeldt \& Sprague, 1992; Lyons \& Alexander, 2000; Montargil, 1995), the inclusion of a variable related to education - in the case, "percentage of graduated residents» - corresponds to the expected. Yet, the presence of the variable "percentages of family cores with children aged less than 15 » is also in line with previous studies, which analyze the impact of having children (Denny \& Doyle, 2009; Plutzer, 2002). Finally, "percentage of classic families» is seen as a measure of population concentration, which is fairly explored in literature (Cancela \& Geys, 2016; Fornos et al., 2004; Kostadinova \& Power, 2007; Mansley \& Demšar, 2015). Although OLS regression exhibits a positive relationship between each one of the explanatory variables and turnout, literature includes both cases of positive and negative relationships.

The explained variance increases when passing from the global to the local models, as verified in the studies that take this methodological approach (Cho \& Gimpel, 2009; Kavanagh et al., 2006; Mansley \& Demšar, 2015; Mota, 2019; Pattie et al., 2015; Taiwo \& Ahmed, 2015). However, and differently from those authors, who achieved the best model using GWR, in this study the best model is only found when a semiparametric approach is taken. Regarding turnout, and as far as is known, semiparametric models have not been used, because usually studies stop with the application of GWR regression. Usually, the problems associated with the use of OLS in the presence of nonstationarity are no longer an issue when applying GWR regression.

The SGWR model contains three global variables (percentage of graduated residents, percentage of classic families and distance to Lisbon or Oporto - the nearest) and two local variables (percentage of family cores with children aged less than 15 and percentage of owner-occupied houses).

Percentage of graduated residents (P_Ind_Res5) and percentage of classic families (P_Famili) have a positive relationship with turnout, the same suggested by OLS regression, while distance to Lisbon or Oporto - the nearest (DLxPorto) is negatively associated with turnout.

For percentage of graduated residents, this positive relationship is confirmed by most of the studies. A higher educational attainment is related to a higher propensity to vote, and college attendance contributes to boost initial turnout (Plutzer, 2002). Considering abstention, voting rates are low among citizens with low levels of educational attainment (Blais et al., 2004; Gallego, 2009; Lyons \& Alexander, 2000; Martins, 2010) and leaving school takes to a decrease in turnout (Huckfeldt \& Sprague, 1992). Contrary, there are studies, one of them regarding portuguese context, where a negative association between lower turnout and third level education is revealed (Kavanagh et al., 2006; Mota, 2019). The positive impact of having a degree can be related to the access and ability to interpret information (Fornos et al., 2004). In fact, educational attainment is used as a measure of ability to interpret information (Jalali, 2003), but it should not be considered detached from other measures (Denny \& Doyle, 2008).

Overall, studies including a measure of population concentration find no evidence regarding the influence of that variable in turnout (Cancela \& Geys, 2016; Fornos et al., 2004; Kostadinova \& Power, 2007). Only Mansley and Demšar (2015) find a positive relationship between population 
density and turnout. It is important to remember that their study respects to a city's election, not a national election, contrary to the aforementioned studies.

Distance to Lisbon or Oporto - the nearest (DLxPorto) is negatively associated with turnout, suggesting that in the interior of the country turnout is lower, since there is a greater distance to the main cities, both located in the coast. This variable can be though as a measure of urbanization, as well as the variable «percentage of classic families». In turn, urbanization is associated with a greater exposure to information and a greater mobility, two factors that increases participation (Fornos et al., 2004). It would mean that turnout would be higher for citizens living in Lisbon or Oporto metropolitan areas. This is not a surprising result, essentially because it refers to a legislative election. Maybe different results would be found in municipal elections, where specific contextual factors and political preferences would probably influence turnout in different ways. Remembering the study of (Martins, 2010), the impact of economy on voting is different in national and local government elections, which suggests that this could happen with other predictors.

Percentage of family cores with children aged less than 15 (P_Nucle_F1) and percentage of owneroccupied houses (P_Res_Hab) are local variables and influence turnout in different ways along the country.

With some exceptions, the percentage of family cores with children aged less than 15 has a positive influence in the coastal north, in Lisbon metropolitan area and in the West region, close to Lisbon. Interestingly, some municipalities belonging to Oporto or Lisbon metropolitan areas constitute exceptions, including Lisbon municipality. In the south, the influence of the percentage of family cores with children aged less than 15 is negative, as well in the interior north. These are reliable results, since the standard errors of this variable are all close to zero.

The negative impact found for having children is in accordance with the results reached by Denny and Doyle (2009) when estimating turnout in people's first election. Also, Plutzer (2002) finds a negative influence when predicting turnout growth, but does not find a significant effect on initial turnout. Regarding the presence of children, no positive effect is described in the studies analyzed. To a better understanding of this phenomenon, it could be important to create measures that distinguish children's age. The exhaustion and time demand associated with raising young children can influence turnout differently from having school-age children, which increase networks that would result in a greater political knowledge (Plutzer, 2002).

The percentage of owner-occupied houses is positively associated with turnout in almost all north region and in a coastal area close to Lisbon, including the city. The effect of this variable is close to zero in almost all south region, existing a central area of the country where it is negative, but weak. Similarly to what happens for the previous variable, it can be said these are reliable results - once more the standard errors of this variable are all close to zero.

The studies analyzed are in line with the results obtained for the north region and the coastal area close to Lisbon. Owner-occupied houses is a measure of population stability, being this, in general, positively related with voting (Cancela \& Geys, 2016; Geys, 2006). In accordance, (Squire et al., 1987) say that home ownership has a strong positive impact on turnout, which can be related to a greater community attachment (Plutzer, 2002). Some authors analyze another measure of population stability, residential mobility, showing that it depresses turnout (Kavanagh et al., 2006; Plutzer, 2002; 
Squire et al., 1987), which underlines the previous results. Yet, (Highton \& Wolfinger, 2001) concludes that residential stability positively influences turnout.

In south region, where the percentage of owner-occupied houses does not influence turnout, the prices of houses are more accessible than the prices in urban areas municipalities. To buy a house in an urban area municipality requires a higher effort when compared to the same situation in the south. Since it is not affordable to everyone, this economic situation creates a higher social distinction, which, in turn, can influence turnout. It can be the case that economic heterogeneity within geographical areas increases the probability of voting (Bartle et al., 2017).

\subsection{RECOMMENDATIONS FOR FUTURE WORKS}

This study contributes to the objective of identifying socioeconomic variables that are related to voter turnout in Portugal and examining if the relationship between those variables and voter turnout varies across the country. Yet, this research answers to the existing lack of studies using quantitative methods in Portugal regarding this issue.

Overall, the results of this study provide evidence to the idea that turnout is a complex process that cannot be satisfactorily explained with a model that does not consider locations. On the other hand, there is also a set of variables that do not vary spatially, which highlight the importance of using SGWR a method which captures the spatial stationarity and nonstationarity in the same model (Nakaya, 2015; Zhao et al., 2016).

Further research could investigate if the results found for the 2011 legislative election hold true for other orders of election, namely presidential and municipal elections, starting with the same variables to allow for comparisons. Future research could also analyze the results of the 2015 and 2019 elections, in order to understand if the relationships identified vary over time.

For future research, and considering a different perspective, other variables should be added to the models, trying to increase the explained variance. Socioeconomic indicators not available on Census can be used, trying to cover the topics presented on literature, namely economic factors and political knowledge and interest. Even for some of the variables here included, different or more measures can be used, for example concerning population stability (Geys, 2006). Homeownership, the variable that measures population stability, might not be the most appropriate in the actual portuguese context, particularly for the younger adults, who are affected by the high prices of houses in urban areas.

To understand what influences the lower levels of voting in Portugal, it is important to continue exploring individual characteristics of citizens, since earlier studies show that political and institutional variables add few information in explaining turnout (Freire \& Magalhães, 2002). Moreover, it might be important to extend the research to other indicators of civic participation, besides turnout, as explored by Tavares and Carr (2013), in order to understand if the variables that influence turnout keep influencing other forms of civic participation. Given the lack of interest concerning political issues (Canas, 2004), it might be important to understand if it is only reflected on turnout, or if it is reflected on other forms of participation. To some extent, an extensive analysis of civic participation might be an indicator of the state of the democracy in our country. 


\section{REFERENCES}

Aldrich, J. H. (1993). Rational Choice and Turnout. American Journal of Political Science, 37(1), $246-$ 278.

Bartle, J., Birch, S., \& Skirmuntt, M. (2017). The local roots of the participation gap: Inequality and voter turnout. Electoral Studies, 48, 30-44. https://doi.org/10.1016/j.electstud.2017.05.004

Baum, M., \& Espírito-Santo, A. (2004). Desigualdades de género em Portugal: a participação política das mulheres. In A. Freire, M. C. Lobo, \& P. Magalhães (Eds.), Portugal a votos. As eleições legislativas de 2002 (pp. 261-299). Imprensa de Ciências Sociais.

Birch, S., \& Lodge, G. U. Y. (2015). Voter Engagement, Electoral Inequality and First-Time Compulsory Voting, 86(3), 385-392.

Blais, A. (2006). What Affects Voter Turnout? Annual Review of Political Science, 9(1), 111-125. https://doi.org/10.1146/annurev.polisci.9.070204.105121

Blais, A., \& Dobrzynska, A. (1998). Turnout in Electoral Democracies. European Journal of Political Research, 33(1981), 239-261. https://doi.org/10.1023/A:1006802916256

Blais, A., Gidengil, E., Nevitte, N., \& Nadeau, R. (2004). Where does turnout decline come from? European Journal of Political Research, 43, 221-236.

Canas, V. (2004). Portugal a votos. As eleições legislativas de 2002. Análise Social, (172), 700-706.

Cancela, J., \& Geys, B. (2016). Explaining voter turnout : A meta-analysis of national and subnational elections. Electoral Studies, 42, 264-275. https://doi.org/10.1016/j.electstud.2016.03.005

Cho, W. K. T., \& Gimpel, J. G. (2009). Presidential Voting and the Local Variability of Economic Hardship. The Forum, 7(1). https://doi.org/10.2202/1540-8884.1286

Clarke, H. D., Scotto, T. J., \& Kornberg, A. (2011). Valence politics and economic crisis : Electoral choice in Canada 2008. Electoral Studies, 30(3), 438-449.

https://doi.org/10.1016/j.electstud.2010.11.006

Creswell, J. W. (2003). Research Design: Qualitative, Quantitative and Mixed Methods Approaches. Sage Publications. https://doi.org/10.3109/08941939.2012.723954

Denny, K., \& Doyle, O. (2008). Political Interest, Cognitive Ability and Personality: Determinants of Voter Turnout in Britain. British Journal of Political Science, 38(02), 291-310. https://doi.org/10.1017/S000712340800015X

Denny, K., \& Doyle, O. (2009). Does voting history matter? Analysing persistence in turnout. American Journal of Political Science, 53(1), 17-35. https://doi.org/10.1111/j.15405907.2008.00355.x

Dettrey, B. J., \& Schwindt-Bayer, L. A. (2009). Voter Turnout in Presidential Democracies. Comparative Political Studies. https://doi.org/10.1177/0010414009332125

Douglas, J. A. (2013). The Foundational Importance of Voting : A Response to Professor Flanders. The. Okla. L. Rev., 66, 81.

Duch, R. M., \& Stevenson, R. (2006). Electoral Studies. Electoral Studies, (3), 528-547.

Endersby, J. W., \& Krieckhaus, J. T. (2008). Turnout around the globe: The influence of electoral 
institutions on national voter participation, 1972-2000. Electoral Studies, 27(4), 601-610. https://doi.org/10.1016/j.electstud.2008.05.004

ESRI. (2016). Regression analysis basics, ArcGIS for Desktop, Tools Reference (ArcMap 10.3). Retrieved from http://desktop.arcgis.com/en/arcmap/10.3/tools/spatial-statisticstoolbox/interpreting-ols-results.htm

Feddersen, T. J. (2004). Rational Choice Theory and the Paradox of Not Voting. Journal of Economic Perspectives, 18(1), 99-112. https://doi.org/10.1257/089533004773563458

Feddersen, T. J., \& Pesendorfer, W. (1996). The Swing Voter's Curse. The American Economic Review, 86(3), 408-424. https://doi.org/10.1111/j.1467-937X.2009.00569.x

Finkel, S. E. (1985). Reciprocal Effects of Participation and Political Efficacy: A Panel Analysis. American Journal of Political Science, 29(4), 891-913.

Fornos, A. C., Power, T., \& Garand, J. (2004). Explaining Voter Turnout in Latin America, 1980 to 2000. Comparative Political Studies, 37(8), 909-940. https://doi.org/10.1177/0010414004267981

Fotheringham, A. S., Brunsdon, C., \& Charlton, M. (2002). Geographically Weighted Regression: The Analysis of Spatially Varying Relationships. West Sussex: John Wiley \& Sons Ltd.

Franklin, M. N. (1992). The Decline of Cleavage Politics. In M. Franklin, T. Mackie, \& H. Valen (Eds.), Electoral Change: Responses to evolving social and attitudinal structures in Western countries. (pp. 383-405). Cambridge: Cambridge University Press.

Franklin, M. N. (2004). Voter Turnout and the Dynamics of Electoral Competition in Established Democracies since 1945. Cambridge: Cambridge University Press. https://doi.org/10.1080/00344890508523327

Freire, A., \& Lobo, M. C. (2005). Economics, ideology and vote: Southern Europe, 1985-2000. European Journal of Political Research, 44(4), 493-518. https://doi.org/10.1111/j.14756765.2005.00236.x

Freire, A., Lobo, M. C., \& Magalhães, P. (Eds.). (2004). Portugal a Votos. As eleições legislativas de 2002. Imprensa de Ciências Sociais.

Freire, A., \& Magalhães, P. (2002). A abstenção eleitoral em Portugal. Imprensa de Ciências Sociais.

Freire, A., \& Santana-Pereira, J. (2012). Economic voting in Portugal, 2002-2009. Electoral Studies, 31(3), 506-512. https://doi.org/10.1016/j.electstud.2012.02.006

Gallego, A. (2009). Where Else Does Turnout Decline Come From? Education, Age, Generation and Period Effects in Three European Countries. Scandinavian Political Studies, 32(1), 23-44. https://doi.org/10.1111/j.1467-9477.2008.00212.x

Gallego, A. (2010). Understanding unequal turnout: Education and voting in comparative perspective. Electoral Studies, 29(2), 239-248. https://doi.org/10.1016/j.electstud.2009.11.002

Geys, B. (2006). Explaining voter turnout: A review of aggregate-level research. Electoral Studies, 25(4), 637-663. https://doi.org/10.1016/j.electstud.2005.09.002

Gray, M., \& Caul, M. (2000). Declining voter turnout in advanced industrial democracies, 1950 to 1997 the effects of declining group mobilization. Comparative Political Studies, 33(9), 10911122. 
Gunther, R., \& Montero, J. R. (2001). The Anchors of P artisanship: A Comparative Analysis of Voting Behavior in Four Southern European Democracies. In P. N. Diamandouros \& R. Gunther (Eds.), Parties, politics and democracy in the new Southern Europe (pp. 83-152). Baltimore: MD: Johns Hopkins University Press. Retrieved from http://books.google.com/books?id=IT2VCWiYRCcC\&pgis=1

Highton, B., \& Wolfinger, R. E. (2001). The First Seven Years of the Political Life Cycle. American Journal of Political Science, 45(1), 202-209.

Hooghe, M., \& Kern, A. (2017). The tipping point between stability and decline: Trends in voter turnout, 1950-1980-2012. European Political Science, (16), 535-552. Retrieved from http://weekly.cnbnews.com/news/article.html?no=124000

Huckfeldt, R., \& Sprague, J. (1992). Political Parties and Electoral Mobilization: Political Structure, Social Structure, and the Party Canvass. The American Political Science Review, 86(1), 70-86. https://doi.org/10.2307/1964016

Inglehart, R., \& Norris, P. (2000). The Developmental Theory of the Gender Gap: Women's and Men's Voting Behavior in Global Perspective. International Political Science Review, 21(4), 441-463.

Jackman, R. W. (1987). Political Institutions and Voter Turnout in the Industrial Democracies. The American Political Science Review, 81(2), 405-424.

Jackman, R. W., \& Miller, R. A. (1995). Voter turnout in the industrial democracies during the 1980s. Comparative Political Studies, 27(4), 467-492.

Jalali, C. (2003). A investigação do comportamento eleitoral em Portugal : história e perspectivas futuras. Análise Social, XXXVIII(167), 545-572.

Johnston, R. J., Pattie, C. J., Dorling, D. F. L., MacAllister, I., Tunstall, H., \& Rossiter, D. J. (2001). Housing tenure, local context, scale and voting in England and Wales, 1997. Electoral Studies, 20(2), 195-216. https://doi.org/10.1016/S0261-3794(00)00008-1

Kavanagh, A., Sinnott, R., Fotheringham, A. S., \& Charlton, M. (2006). A Geographically Weighted Regression Analysis of General Election Turnout in the Republic of Ireland.Paper presented to the Political Studies Association of Ireland Conference, University College Cork.

Kostadinova, T. (2003). Voter turnout dynamics in post-Communist Europe. European Journal of Political Research, 42(6), 741-759. https://doi.org/10.1111/1475-6765.00102

Kostadinova, T., \& Power, T. J. (2007). Does Democratization Depress Participation? Political Research Quarterly, 60(3), 363-377.

Kostelka, F. (2017). Does democratic consolidation lead to a decline in voter turnout? Global evidence since 1939. American Political Science Review, 111(4), 653-667. https://doi.org/10.1017/S0003055417000259

Ladner, A., \& Milner, H. (1999). Do Voters Turn Out More Under Proportional than Majoritarian Systems? The Evidence from Swiss Communal Elections. Electoral Studies, 18(2), 235-250. https://doi.org/10.1016/S0261-3794(98)00052-3

Lewis-Beck, M. S., \& Stegmaier, M. (2000). Economic determinants of electoral outcomes. Annual Review of Political Science, 3, 183-219.

Lijphart, A. (1997). Unequal Participation: Democracy's Unresolved Dilemma. The American Political 
Science Review, 91(1), 1-14.

Lyons, W., \& Alexander, R. (2000). A Tale of Two Electorates: Generational Replacement and the Decline of Voting in Presidential Elections. The Journal of Politics, 62(4), 1014-1034.

Magalhães, P. (2008). Redes sociais e participação eleitoral. Análise Social, 473-504.

Mansley, E., \& Demšar, U. (2015). Space matters: Geographic variability of electoral turnout determinants in the 2012 London mayoral election. Electoral Studies, 40, 322-334. https://doi.org/10.1016/j.electstud.2015.10.003

Martins, R. C. de A. (2010). Análise Económica do Comportamento Eleitoral em Portugal (unpublished doctoral thesis). Universidade de Coimbra.

Matsusaka, J. G. (1995). Explaining voter turnout patterns : An information theory. Public Choice, 84, 91-117.

Montargil, F. (1995). Determinantes Sociais da Abstenção Eleitoral - análise da eleição legislativa de 1991 (dissertação final de licenciatura). Instituto Superior de Ciências do Trabalho e da Empresa da Universidade de Lisboa. Retrieved from

http://www.cne.pt/sites/default/files/dl/miolo_determinantes_sociais.pdf

Mota, A. M. S. (2019). Modelling Abstention Rate using Spatial Regression (unpublished master thesis). NOVA IMS - Information Management School.

Nakaya, T. (2015). Geographically weighted generalised linear modelling. Geocomputation: A Practical Primer, 217, 20.

Nakaya, T., Fotheringham, A. S., Brunsdon, C., \& Charlton, M. (2005). Geographically weighted Poisson regression for disease association mapping. Statisitics in Medicine, 24(17), 2695-2717. https://doi.org/10.1002/sim.2129

Nakaya, T, Fotheringham, A. S., Charlton, M., \& Brunsdon, C. (2009). Semiparametric geographically weighted generalised linear modelling in GWR 4.0. In Lees Editor (Ed.), 10th International Conference on GeoComputation, UNSW, Sydney, November-December, 2009 (pp. 1-5). UNSW, Sydney.

Nakaya, Tomoki, Charlton, M., Brunsdon, C., Lewis, P., Yao, J., \& Fotheringham, A. S. (2016). GWR4.09 User Manual.

Nevitte, N., Blais, A., Gidengil, E., \& Nadeau, R. (2009). Socioeconomic Status and Nonvoting: A CrossNational Comparative Analysis. The Comparative Study of Electoral Systems, (November 2015), 85-108.

Nezi, R. (2012). Economic voting under the economic crisis: Evidence from Greece. Electoral Studies, 31(3), 498-505. https://doi.org/10.1016/j.electstud.2012.02.007

Nunes, F. (2005). Eleições de segunda ordem em Portugal: o caso das europeias de 2004. Análise Social, 40(177), 795-813.

O'brien, R. M. (2007). A caution regarding rules of thumb for variance inflation factors. Quality and Quantity, 45(5), 673-690.

Pattie, C. J., Johnston, R. J., Schipper, M., \& Potts, L. (2015). Are Regions Important in British Elections? Valence Politics and Local Economic Contexts at the 2010 General Election. Regional Studies, 49(9), 1561-1574. https://doi.org/10.1080/00343404.2013.847271 
Plutzer, E. (2002). Becoming a Habitual Voter: Inertia, Resources, and Growth in Young Adulthood, 96(1), 41-56.

PORDATA - Base de Dados Portugal Contemporâneo. (n.d.). Retrieved November 5, 2015, from http://www.pordata.pt/Portugal/Eleitores+nas+eleições+para+a+Assembleia+da+República+tot al++votantes+e+abstenção-2181

Ribeiro, E. A., Borba, J., \& da Silva, R. (2015). Comparecimento eleitoral na América Latina: uma análise multinível comparada. Revista de Sociologia e Política, 23(54), 91-108. https://doi.org/10.1590/1678-987315235406

Romero, M., \& Fox, J. (2016). Uneven Landscape: Mapping Underrepresentation of Young Adults in California's Electorate. National Civic Review, 105(4), 40-51. https://doi.org/10.1002/ncr.21300

Rosenshein, L., \& Scott, L. (2012). Spatial Statistics: Best Practices. Technical Workshop. Esri International User Conference. San Diego, CA: ESRI. Retrieved from https://www.esri.com/videos/watch?videoid=ypCM8P-pxLQ\&title=Esri 2012 UC Tech Session\%3A Spatial Statistics\%3A Best Practices

Rosenshein, Lauren, Scott, L., \& Pratt, M. (2011). Finding a Meaningful Model This checklist will help you evaluate regression models. ArcUser, 40-45.

Sanders, D. (2000). The real economy and the perceived economy in popularity functions: how much do voters need to know ? A study of British data , 1974-97. Electoral Studies, 19, 275-294.

Sanders, D. (2005). The political economy of UK party support, 1997-2004: Forecasts for the 2005 general election. Journal of Elections, Public Opinion and Parties, 15(1), 47-71. https://doi.org/10.1080/13689880500064585

Schlozman, K. L., Burns, N., \& Verba, S. (1994). Gender and the Pathways to Participation: The Role of Resources. The Journal of Politics, 56(4), 963-990.

Squire, P., Wolfinger, R. E., \& Glass, D. P. (1987). Residential Mobility and Voter Turnout. The American Political Science Review, 81(1), 45-66.

Stoker, L., \& Jennings, M. K. (1995). Life-Cycle Transitions and Political Participation: The Case of Marriage. The American Political Science Review, 89(2), 421-433.

Strate, J. M., Parrish, C. J., Elder, C. D., \& Coit, F. (1989). Life Span Civic Development and Voting Participation. The American Political Science Review, 83(2), 443-464.

Taiwo, O. J., \& Ahmed, F. (2015). Geographical analysis of voter apathy in presidential elections between 1999 and 2011 in Nigeria. African Geographical Review, 34(3), 250-268. https://doi.org/10.1080/19376812.2015.1009381

Tavares, A. F., \& Carr, J. B. (2013). So close, yet so far away? The effects of city size, density and growth on local civic participation. Journal of Urban Affairs, 35(3), 283-302. https://doi.org/10.1111/j.1467-9906.2012.00638.x

Timpone, R. J. (1998). Structure, Behavior, and Voter Turnout in the United States. The American Political Science Review, 92(1), 145-158.

Viegas, J. M. L., \& Faria, S. (2004). A abstenção nas eleições legislativas de 2002. In A. Freire, M. Costa Lobo, \& P. Magalhães (Eds.), Portugal a votos. As eleições legislativas de 2002 (pp. 221-259). Imprensa de Ciências Sociais. 
Wass, H. (2007). The effects of age, generation and period on turnout in Finland 1975-2003.

Electoral Studies, 26, 648-659. https://doi.org/10.1016/j.electstud.2007.06.002

Zhao, Q., Wentz, E., Fotheringham, S., Yabiku, S., Hall, S., Glick, J., ... Heavenrich, H. (2016).

Semiparametric Geographically Weighted Regression (S-GWR): a Case Study on Invasive Plant Species Distribution in Subtropical Nepal. In International Conference on GIScience Short Paper Proceedings (pp. 396-399). https://doi.org/10.21433/b3118kv3n3bq 

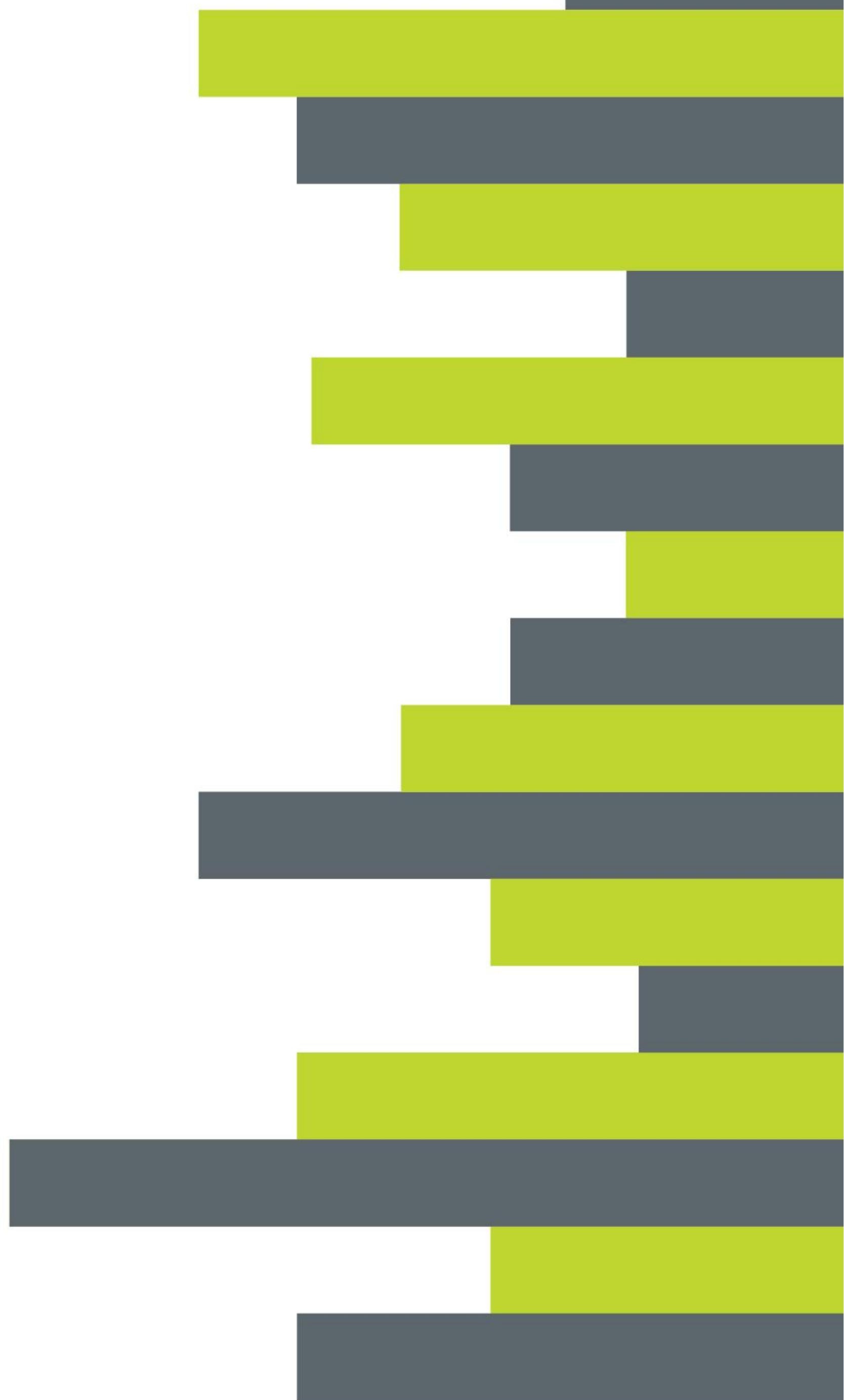